Research, Society and Development, v. 9, n. 10, e279108339, 2020

(CC BY 4.0) | ISSN 2525-3409 | DOI: http://dx.doi.org/10.33448/rsd-v9i10.8339

\title{
Uma revisão bibliográfica sobre bokashi dos últimos 20 anos
}

A bibliographic review on bokashi from the last 20 years

Una revisión bibliográfica sobre bokashi de los últimos 20 años

Recebido: 10/09/2020 | Revisado: 13/09/2020 | Aceito: 15/09/2020 | Publicado: 17/09/2020

Nelma Ferreira de Paula Vicente

ORCID: https://orcid.org/0000-0001-5874-7076

Universidade Federal de Lavras, Brasil

E-mail: nellmaferreira@ hotmail.com

Érica Alves Marques Marafeli

ORCID: https://orcid.org/0000-0003-1382-5012

Universidade Federal de Lavras, Brasil

E-mail: ericagroeng@yahoo.com.br

Júlia Assunção de Castro Oliveira

ORCID: https:// orcid.org/0000-0001-8358-2832

Universidade Federal de Lavras, Brasil

E-mail: julia.assuncaooliveira@hotmail.com

José Luiz Choiti Tomita

ORCID: https://orcid.org/0000-0003-2817-4646

Korin Preservação e Recuperação do Meio Ambiente Ltda, Brasil

E-mail: jlctomita@gmail.com

Roberta Hilsdorf Piccoli

ORCID: https://orcid.org/0000-0003-2334-9400

Universidade Federal de Lavras, Brasil

E-mail: rob.hilsdorf@gmail.com

\section{Resumo}

Um fertilizante orgânico que cada vez mais tem ganhado espaço na agricultura é o bokashi. O bokashi é resultante de um método de compostagem baseado na adição de solução líquida de microrganismos efetivos, que são bactérias anaeróbicas e fermentos do ácido láctico. Uma técnica do Japão que foi adaptada para o Brasil no final da década de 80 por imigrantes japoneses. No Brasil, ele é conhecido como "Fermento da Vida", por trazer vida ao solo, aumentando o número e a diversidade dos microrganismos que vivem no mesmo. Nota-se que 
o conhecimento científico sobre o bokashi ainda não foi muito explorado, além disso, não se encontra na literatura uma pesquisa bibliográfica sobre este adubo orgânico. Neste contexto, objetivou-se nesta pesquisa, sistematizar os estudos realizados sobre bokashi nas áreas de agricultura e ciências biológicas, ciência ambiental, bioquímica, genética e biologia molecular, imunologia e microbiologia, engenharia química, energia, multidisciplinar, química, ciências sociais e veterinária. O presente trabalho foi realizado por meio do instrumento de pesquisa Periódico Capes, através das bases Scopus e Web Of Science (WOS). Para ambas as bases foram utilizadas as seguintes palavras chaves: bokashi; para baixar os documentos pesquisados foi utilizado o Software EndNote X7. A pesquisa foi realizada no dia 01 de julho de 2019. Por meio desta pesquisa de revisão pode-se concluir que mais de 50\% dos artigos publicados sobre bokashi nos últimos 20 anos de pesquisas são voltados para a área de agricultura e ciências biológicas e ciências ambientais, demonstrando que outras áreas como veterinária, ciências sociais, química, multidisciplinar, energia, engenharia química, imunologia e microbiologia, bioquímica, genética e biologia molecular, são escassas em pesquisas relacionadas ao adubo.

Palavras-chave: Fertilizante orgânico; Microrganismos efetivos; Adubo fermentado.

\section{Abstract}

An organic fertilizer that is increasingly gaining ground in agriculture is bokashi. Bokashi is the result of a composting method based on the addition of a liquid solution of effective microorganisms, which are anaerobic bacteria and lactic acid yeasts. A technique from Japan that was adapted to Brazil in the late 1980s by Japanese immigrants. In Brazil, it is known as "Fermento da Vida", for bringing life to the soil, increasing the number and diversity of microorganisms that live in it. It is noted that the scientific knowledge about bokashi has not been explored much, besides, there is no bibliographical research on this organic fertilizer. In this context, the objective of this research was to systematize the studies carried out on bokashi in the areas of agriculture and biological sciences, environmental science, biochemistry, genetics and molecular biology, immunology and microbiology, chemical engineering, energy, multidisciplinary, chemistry, social and veterinary sciences. The present work was carried out using the research instrument Periódico Capes, through the Scopus and Web Of Science (WOS) databases. For both bases, the following keywords were used: bokashi; to download the searched documents, the EndNote X7 Software was used. The survey was conducted on July 1, 2019. Through this review survey, it can be concluded that more than $50 \%$ of the articles published on bokashi in the last 20 years of research are 
focused on the area of agriculture and biological sciences and sciences environmental, demonstrating that other areas such as veterinary, social sciences, chemistry, multidisciplinary, energy, chemical engineering, immunology and microbiology, biochemistry, genetics and molecular biology, are scarce in research related to fertilizer.

Keywords: Organic fertilizer; Effective microorganisms; Fermented fertilizer.

\section{Resumen}

Un fertilizante orgánico que gana cada vez más terreno en la agricultura es el bokashi. Bokashi es el resultado de un método de compostaje basado en la adición de una solución líquida de microorganismos efectivos, que son bacterias anaeróbicas y levaduras de ácido láctico. Una técnica de Japón que fue adaptada a Brasil a finales de los 80 por inmigrantes japoneses. En Brasil, se le conoce como "Fermento da Vida", por traer vida al suelo, aumentando el número y diversidad de microorganismos que viven en él. Se observa que aún no se ha explorado el conocimiento científico sobre el bokashi, además, no existe una investigación bibliográfica sobre este fertilizante orgánico. En este contexto, el objetivo de esta investigación fue sistematizar los estudios realizados sobre bokashi en las áreas de agricultura y ciencias biológicas, ciencias ambientales, bioquímica, genética y biología molecular, inmunología y microbiología, ingeniería química, energía, multidisciplinar, química, ciencias sociales y veterinarias. El presente trabajo se realizó utilizando el instrumento de investigación Periódico Capes, a través de las bases de datos Scopus y Web Of Science (WOS). Para ambas bases, se utilizaron las siguientes palabras clave: bokashi; para descargar los documentos buscados, se utilizó el software EndNote X7. La encuesta se realizó el 1 de julio de 2019. A través de esta encuesta de revisión, se puede concluir que más del $50 \%$ de los artículos publicados sobre bokashi en los últimos 20 años de investigación están enfocados en el área de agricultura y ciencias y ciencias biológicas. ambiental, demostrando que otras áreas como veterinaria, ciencias sociales, química, multidisciplinar, energía, ingeniería química, inmunología y microbiología, bioquímica, genética y biología molecular, son escasas en las investigaciones relacionadas con fertilizantes.

Palabras clave: Abono orgánico; Microorganismos eficaces; Fertilizante fermentado.

\section{Introdução}

Após o início de cultivos mais extensos na agricultura, o uso de adubos orgânicos vem perdendo espaço para fertilizantes químicos, a consequência dessa prática pode contribuir 
cada vez mais em processos de degradação, erosão e contaminação dos solos, aumentando o custo de produção das lavouras. Com isso a procura por diferentes técnicas para um melhor aproveitamento do solo, vem ganhando espaço com a utilização de produtos orgânicos ou menos nocivos ao meio ambiente (Souza, 2018).

Em solos tropicais, como os brasileiros a reposição periódica de matéria orgânica torna-se de extrema importância, devido a sua rápida decomposição e alto grau de intemperismo causado pela incidência de chuvas e altas temperaturas típicas desse ambiente, embora estes sejam considerados pobres em nutrientes, eles geralmente têm boa profundidade e, em seu estado natural, têm estrutura porosa e agregada, o que facilita o aprofundamento das raízes e maior exploração no espaço (Curi et al, 2017).

Solos tropicais produzem mais biomassa e maior atividade biológica, que rapidamente recicla a matéria orgânica produzida, disponibilizando nutrientes para as plantas e para outros seres vivos, sendo necessário sua constante adubação e atenção aos processos físicos e biológicos, altamente dependentes da adição periódica de matéria orgânica (Nikitin et al. 2018). Com o propósito de melhorar as características físicas, químicas e biológicas do solo, o uso de adubos orgânicos, se tornou prática frequente pois estes são fonte de energia e nutrientes para processos químicos e ciclos biológicos dos organismos do solo, mantendo os mesmos em estado dinâmico e exercendo importante papel em sua fertilidade (Quiroz \& Flores, 2019).

Neste contexto, um composto orgânico que cada vez mais ganha espaço na agricultura é o bokashi, um fertilizante orgânico, resultante de um método de compostagem baseado na adição de solução líquida de microrganismos efetivos, que são bactérias anaeróbicas e fermentos do ácido láctico. É um concentrado, rico em nitrogênio, fósforo e potássio, para a substituição dos fertilizantes químicos tradicionais, podendo ser aplicado por ocasião do plantio ou em cobertura, sua proposta principal é de aumentar a produtividade das plantas e a qualidade dos produtos agrícolas gerados (Hikamah, Sudiarti \& Hasbiyati, 2019).

Além do fornecimento de nutrientes, o bokashi carreia para o solo microrganismos regeneradores (fungos, bactérias, actinomicetos, micorrizas, fixadores de nitrogênio), os quais atuam promovendo a fermentação da biomassa, rapidamente estabelecendo condições favoráveis à multiplicação de outros componentes benéficos da biota (Laskowska, Jarosz, Grądzki, 2018). O bokashi pode ser proveniente de farelos (soja, milho, arroz, trigo, dentre outros), ou seja, uma mistura balanceada de matérias de origem vegetal e/ou animal e mineral que passam por uma fermentação. É uma técnica do Japão que foi adaptada ao Brasil no final da década de 80 por imigrantes japoneses. No Brasil, ele é conhecido como "Fermento da 
Vida", porque traz vida ao solo, aumentando o número e a diversidade dos microrganismos que vivem no mesmo (Curi et al, 2017). De acordo com Souza \& Rezende (2003), a composição do bokashi pode variar de um preparo para outro, com valores nutricionais aproximadamente de: $\mathrm{N}=3 \% ; \mathrm{P}=2 \% ; \mathrm{K}=1,4 \% ; \mathrm{Ca}=2,2 \% ; \mathrm{Mg}=1,1 \% ; \mathrm{Mn}=0,018 \%$; $\mathrm{Zn}=0,011 \% ; \mathrm{Fe}=0,090 \% ; \mathrm{B}=0,020 \% ; \mathrm{Cu}=0,010 \% ; \mathrm{pH}=6,0$ e relação $\mathrm{C} / \mathrm{N}=12: 1)$. Segundo eles, o uso de doses crescentes destes fertilizantes pode afetar diretamente o acúmulo de massa seca, devido a maior disponibilidade de nutrientes no solo.

Contudo nota-se que o conhecimento científico sobre o bokashi ainda não foi muito explorado, e também por não se encontrar na literatura uma pesquisa bibliográfica sobre este adubo orgânico, objetivou-se nesta pesquisa, sistematizar os estudos realizados sobre bokashi nas áreas de agricultura e ciências biológicas, ciência ambiental, bioquímica, genética e biologia molecular, imunologia e microbiologia, engenharia química, energia, multidisciplinar, química, ciências sociais e veterinária.

\section{Metodologia}

O presente trabalho apresenta caráter quali-quantitativo de acordo com Pereira et al., (2018) e foi realizado por meio do instrumento de pesquisa Periódico Capes, através das bases Scopus e Web Of Science (WOS). Para ambas as bases foram utilizadas a seguinte palavrachave: bokashi; para baixar os documentos pesquisados se utilizou o Software EndNote.X $7^{\circledR}$. A pesquisa foi realizada no dia 01 de julho de 2019, não sendo realizado recorte temporal.

$\mathrm{Na}$ base de dados Scopus foram encontrados 75 documentos relacionados ao adubo orgânico bokashi, mas fazendo uma fintragem apenas por artigos foram encontrados 67 artigos científicos, já na base de dados WOS foram encontrados 72 documentos relacionas ao bokashi, quando realizada a filtragem em busca apenas de artigos, foram encontrados 57. Após reuni-los em uma única pasta (124 artigos), foi executada a exclusão das duplicatas (documentos presentes nas duas bases) por meio do gerenciador de bibliografia (EndNote), onde após esse procedimento foram obtidos 70 documentos (Figura 1). 
Figura 1. Documentos encontrados nas bases Scopus e Web Of Science (WOS).

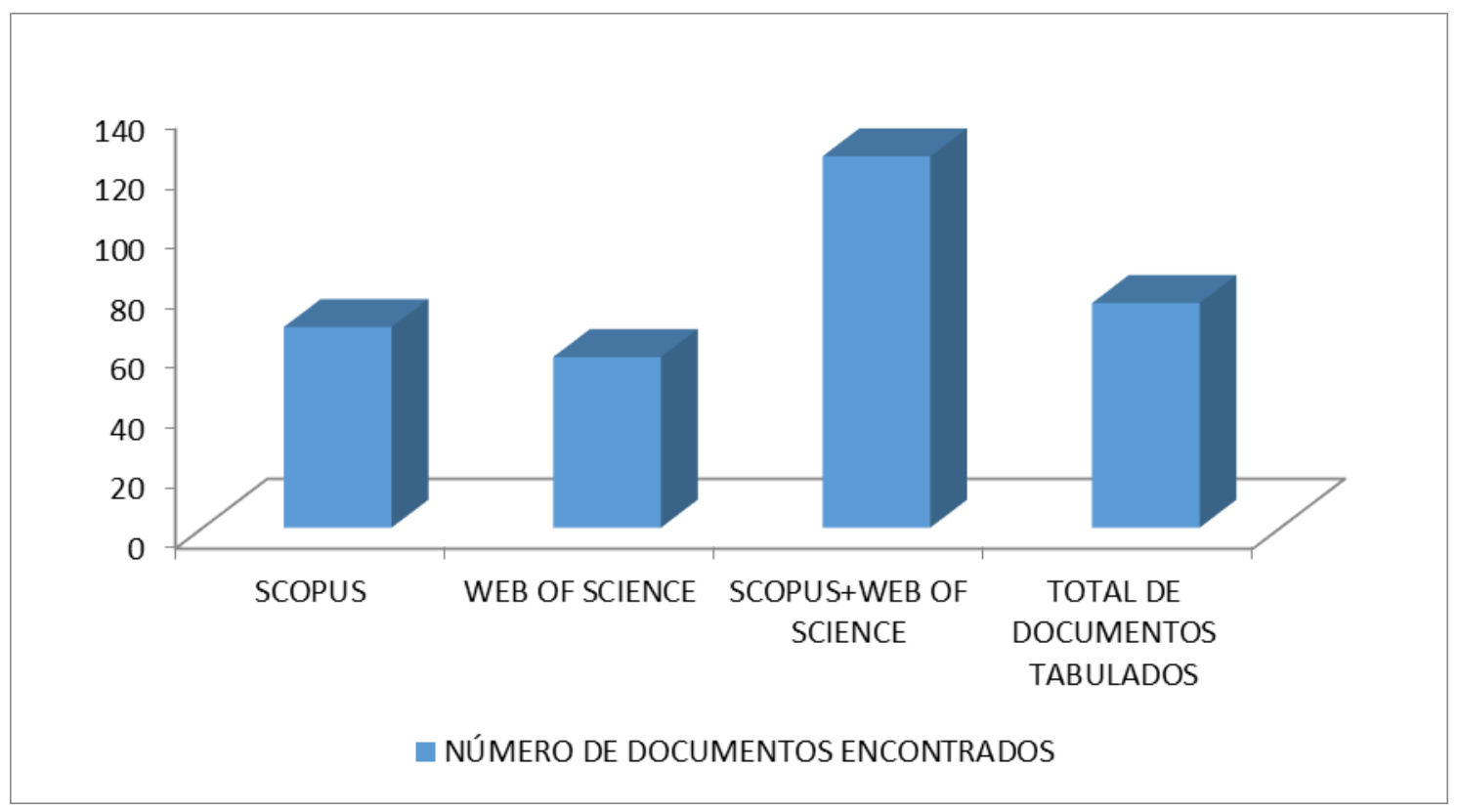

Fonte: Adaptado Scopus (2019).

Na Figura 1 é possível observar o número de documentos encontrados em cada base utilizada e o total de documentos tabulados. Após essa etapa foi montada uma planilha no Softwer Excel para tabulação de cada artigo, estes foram selecionados a partir dos títulos e seus resumos que estavam de acordo com o tema. Para a criação da tabela extraiu-se as informações contidas nos artigos como: autor, ano, título, objetivo, espécies estudadas, tipo de adubo, foco do estudo, metodologia e conclusão.

\section{Resultados e Discussão}

$\mathrm{Na}$ base de dados Scopus foi encontrado o maior número de artigos científicos e quando comparados estes com a base WOS, retirando as duplicatas, foram encontrados 3 artigos a mais na base Scopus que não estavam presentes na base WOS, são eles (Xavier et al., 2019; Ndona et al, 2011 e Park \& Kremer, 2010).

Na Tabela 1, é apresentado o número de documentos publicados sobre o adubo orgânico bokashi de 1999 a 2019. 
Research, Society and Development, v. 9, n. 10, e279108339, 2020

(CC BY 4.0) | ISSN 2525-3409 | DOI: http://dx.doi.org/10.33448/rsd-v9i10.8339

Tabela 1. Número de documentos publicados sobre o adubo orgânico bokashi de 1999 a 2019.

\begin{tabular}{|c|c|}
\hline Ano de publicação & $\mathrm{N}^{\circ}$ de documentos publicados \\
\hline 2019 & 5 \\
\hline 2018 & 6 \\
\hline 1017 & 6 \\
\hline 2016 & 6 \\
\hline 2015 & 5 \\
\hline 2014 & 7 \\
\hline 2013 & 3 \\
\hline 2012 & 4 \\
\hline 2011 & 4 \\
\hline 2010 & 6 \\
\hline 2009 & 3 \\
\hline 2007 & 1 \\
\hline 2006 & 1 \\
\hline 2002 & 1 \\
\hline 2000 & 3 \\
\hline 1999 & 1 \\
\hline
\end{tabular}

Fonte: Adaptado Scopus (2019).

Nota-se que em 20 anos de pesquisas realizada sobre o adubo orgânico bokashi, não houve uma evolução em relação a artigos publicados, mas podemos destacar o ano de 2014 que apresentou o maior número de publicações com sete artigos e os anos de 1999, 2002, 2006 e 2007 com apenas um artigo publicado.

$\mathrm{Na}$ Tabela 2 é apresentada a relação dos 10 autores que mais publicaram sobre o assunto. 
Research, Society and Development, v. 9, n. 10, e279108339, 2020

(CC BY 4.0) | ISSN 2525-3409 | DOI: http://dx.doi.org/10.33448/rsd-v9i10.8339

Tabela 2. Relação dos 10 autores que mais publicaram sobre o adubo orgânico bokashi.

\begin{tabular}{cl}
\hline Autor & $\mathbf{N}^{\mathbf{0}}$ de documentos publicados \\
\hline Xu, H.L. & 4 \\
Alvarez-Solís, J.D. & 4 \\
Barajas-Aceves,M. & 3 \\
Dias-Arieira, C.R. & 3 \\
Gutiérrez-Miceli, F.A. & 3 \\
Becerril-Román, A.E. & 2 \\
Cornelissen, G. & 2 \\
Daiss. N. & 2 \\
Gonzalez. M. & 2 \\
Gradzki, Z. & 2 \\
\hline
\end{tabular}

Fonte: Adaptado Scopus (2019).

É possível observar que dos 10 autores que mais publicaram sobre bokashi, apenas dois se destacam: Xu, H.L. e Alvarez-Solís, J.D., com quatro artigos publicados cada um. Com isso, pode-se perceber que ainda é pouco o número de pesquisas realizadas e pesquisadores que se interessam sobre a área.

Em relação ao número de documentos por área pesquisada é possível observar na Tabela 3 as áreas e porcentagens de publicações de artigos que apresentam pesquisas com o adubo orgânico bokashi. 
Research, Society and Development, v. 9, n. 10, e279108339, 2020

(CC BY 4.0) | ISSN 2525-3409 | DOI: http://dx.doi.org/10.33448/rsd-v9i10.8339

Tabela 3. Porcentagem de artigos publicados por área.

\begin{tabular}{cc}
\hline Área & \% de Publicação \\
\hline Veterinária & 2 \\
Ciências Sociais & 2 \\
Química & 2,09 \\
Multidisciplinar & 4,09 \\
Energia & 4,09 \\
Engenharia Química & 5,1 \\
Imunologia e Microbiologia & 8,1 \\
Bioquímica, Genética e Biologia Molecular & 9,1 \\
Ciência Ambiental & 14,1 \\
Agricultura e Ciências Biológicas & 46,5 \\
\hline
\end{tabular}

Fonte: Adaptado Scopus (2019).

Nota-se que as principais áreas com estudos em bokashi que apresentam maior percentual de artigos publicados foram: agricultura e ciências biológicas com 46,5\% e ciência ambiental com $14,1 \%$ o que corresponde a mais de $50 \%$ das pesquisas dedicadas a área de agricultura e ciências biológicas e ciência ambiental.

Na Tabela 4 é apresentada a relação dos 46 artigos com estudos apenas na área de agricultura e ciências biológicas, onde as principais informações extraídas foram: autor, ano, título, espécies estudadas, tipo de adubo, foco do estudo e metodologia.

Tabela 4. Artigos de pesquisas com foco em agricultura e ciências biológicas.

\section{Agricultura e Ciências Biológicas}

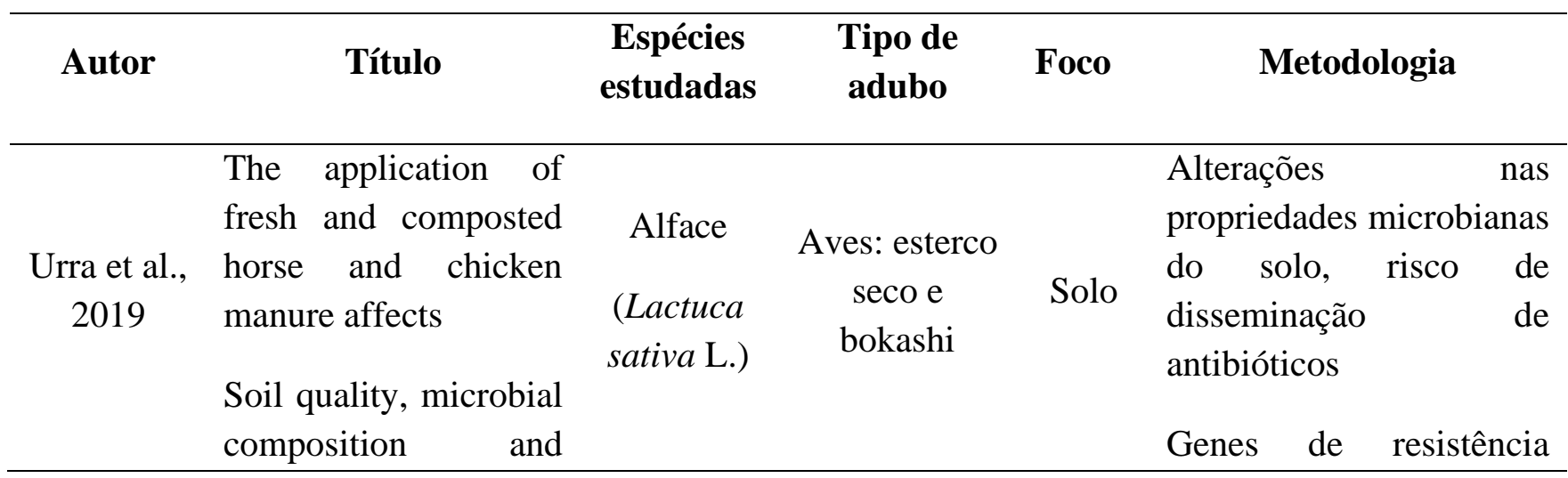


antibiotic resistance

Nitrogen availability, maturity and stability

Quiroz \& of bokashi-type

Flores, fertilizers elaborated 2019 with different feedstocks of animal origin

Nutrient effect of various composting

Pandit et methods with and al., 2019 without biochar on soil fertility and maize growth
Milho

(Zea mays

L.)
Aves e suínos

bokashi

(WVP); contém palha de trigo e resíduos vegetais; WVP e WVS

\section{Compostage}

$\mathrm{m}$

convencional

(processo de compostagem

concluído

sem virar as

estacas),

compostagem aeróbia

(processo de compostagem

com giro manual de estacas) e compostagem de bokashi (lacto fermentação anaeróbia). (args) através da transferência horizontal de genes (HGT).

A temperatura, $\mathrm{N}$ mineral, $\mathrm{pH}, \quad \mathrm{CE}$, produção de $\mathrm{CO} 2$

Taxa e índice de germinação (IG) foram medidos
Análises de biomassa,

Solo crescimento, análise do solo

Redesign of the traditional

Mesoamerican

Reynaagroecosystem based

Ramírez et

al, 2018 on participative ecological intensification:

Milho e feijão

(Zea mays Adubos orgânicos (sólidos e $\mathrm{e}$

Phaseolus orgânicos) e

Evaluation of the soil and efficiency of the vulgaris sintéticos.

Análise de solo, índices de eficiência econômica, Solo uso de mão-de-obra e fertilizantes e índices de produtividade system 


\begin{tabular}{|c|c|c|c|c|c|}
\hline $\begin{array}{l}\text { Resman et } \\
\text { al, } 2018\end{array}$ & $\begin{array}{l}\text { Effect of bokashi } \\
\text { fertilizer on growth } \\
\text { and yield of local } \\
\text { maize from Muna } \\
\text { Island under net house } \\
\text { treatment in West } \\
\text { Muna Southeast } \\
\text { Sulawesi, Indonesia }\end{array}$ & Milho & Bokashi & $\begin{array}{l}\text { Casa } \\
\text { de } \\
\text { vegeta } \\
\text { ção }\end{array}$ & $\begin{array}{l}\text { Altura da planta, } \\
\text { diâmetro do caule, } \\
\text { número de folhas, área } \\
\text { foliar, diâmetro da } \\
\text { espiga, comprimento da } \\
\text { espiga sem casca, peso } \\
\text { da espiga sem casca e } \\
\text { casca. }\end{array}$ \\
\hline $\begin{array}{l}\text { Lasmini, } \\
\text { et al, } 2018\end{array}$ & $\begin{array}{l}\text { Improvement of soil } \\
\text { quality using bokashi } \\
\text { composting and NPK } \\
\text { fertilizer to increase } \\
\text { shallot yield on dry } \\
\text { land }\end{array}$ & $\begin{array}{l}\text { Gliricidia } \\
\text { Kunth } s p \text {. } \\
\text { Folhas de } \\
\text { árvores }\end{array}$ & $\begin{array}{c}\text { Esterco de } \\
\text { vaca e NPK }\end{array}$ & Solo & $\begin{array}{l}\text { A análise dos } \\
\text { microrganismos do solo e } \\
\text { do solo }\end{array}$ \\
\hline $\begin{array}{l}\text { Sumarni, } \\
\text { Aini, } \\
\text { Fajriani et } \\
\text { al., } 2017\end{array}$ & $\begin{array}{l}\text { The application of } \\
\text { compost and } \\
\text { arbuscularmy } \\
\text { corrhizal fungi to } \\
\text { increase efficiency of } \\
\text { inorganic fertilization } \\
\text { on maize (Zea mays } \\
\text { L.) }\end{array}$ & Milho & $\begin{array}{c}\text { Fertilizantes } \\
\text { inorgânicos }\end{array}$ & $\begin{array}{l}\text { Solo } \\
\text { mais } \\
\text { fungo } \\
\text { s } \\
\text { Arbus } \\
\text { culare } \\
\quad s \\
\text { corríz } \\
\text { icos }\end{array}$ & Análise de solo \\
\hline $\begin{array}{l}\text { Shin et al, } \\
2017\end{array}$ & $\begin{array}{l}\text { Variability } \\
\text { Effective } \\
\text { organisms }(\mathrm{EM}) \text { in } \\
\text { bokashi and soil and } \\
\text { effects on soil-borne } \\
\text { plant pathogens }\end{array}$ & $\begin{array}{l}\text { Pepino e } \\
\text { cenoura } \\
\text { (Cucumis } \\
\text { sativus L. } \\
\text { e Daucus } \\
\text { carota L.) }\end{array}$ & $\begin{array}{c}\text { EM-bokashi } \\
\text { ou EM- } \\
\text { bokashi } \\
\text { esterilizado }\end{array}$ & $\begin{array}{l}\text { Solo } \\
\text { mais } \\
\text { EM }\end{array}$ & $\begin{array}{l}\text { Análise da respiração do } \\
\text { solo e a eletroforese em } \\
\text { gel de gradiente } \\
\text { desnaturante (DGGE) }\end{array}$ \\
\hline $\begin{array}{l}\text { Hanafiah } \\
\text { et al, } 2017\end{array}$ & $\begin{array}{l}\text { Biogas production } \\
\text { from goat and chicken } \\
\text { manure in Malaysia }\end{array}$ & $\begin{array}{c}\text { Cabra e } \\
\text { aves }\end{array}$ & Bokashi & $\begin{array}{l}\text { Produ } \\
\text { ção de } \\
\text { gás } \\
\text { metan } \\
\text { o }\end{array}$ & $\begin{array}{l}\text { Determinar } \\
\text { características biofísicas } \\
\text { do substrato utilizando a } \\
\text { Demanda Química de } \\
\text { Oxigênio } \\
\text { nutrientes, } \\
\text { pesados, análises de } \\
\text { carbono para Nitrogênio } \\
\text { e nitrogênio amoniacal e } \\
\text { teste potencial de bio } \\
\text { metano }\end{array}$ \\
\hline
\end{tabular}


Ferreira et the control of al, 2017 Meloidogyne javanica in lettuce, in greenhouse

Manure effect on the

Ribeiro et al, 2016 incidence of rose diseases in the Integrated Production System

Mineral and organic fertilization influence

Hoshino et al, 2016 on the development of cattlianthe 'chocolate drop'

Alface

Bokashi

Ação

do

nemat

oide das galhas (Melo idogy ne javani

ca)

Adubação

química

recomendada

para roseiras,

Rosa

adubo verde

(Calopogoniu $m$

mucunoides)

e supermagro

Fertilizante

mineral ultrasolúvel,

mistura de

farinha de

mamona e

farinha de

ossos

\section{Diferentes}

Tomato yield and

França et quality under various

al, 2016 combinations organic compost

$\begin{array}{cl}\text { Baldotto } & \text { Initial performance of } \\ \& & \text { corn in response to } \\ \text { Baldotto, } & \text { treatment of seeds } \\ 2016 & \text { with humic acids }\end{array}$

Tomate porcentagens

(Santa de cama de

Clara e o

híbrido

Verano) da
Desen

volvi Avaliaram-se diferentes mento formulações de cama de da frango e esmagado cana espéci de açúcar

Avaliações da doença foram realizadas Contr semanalmente nas folhas ole de centrais dos talos de pragas flores produtivos $\mathrm{e}$ manejo integrado de doenças

Desenvolvimento da parte aérea e o acúmulo de nutrientes foram avaliados, peso seco de raiz e parte aérea

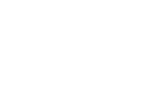


isolated from bokashi

Effect of Bokashi and vermicompost

leachate on yield and

Álvarez- quality of pepper

Solís et al, (Capsicum annuum)

2016 and onion (Allium сера) under monoculture and intercropping cultures

Nutritional foliar

Peralta- status of three mango Antonio et cultivars fertilized al, 2015 with organic amendments

Short-term changes in fertility attributes and

Lima et al, soil organic matter 2015 caused by the addition of em Bokashis in two tropical soils

Use of organic

Dias- amendments in the Arieira et management of rootal, 2015 knot nematode in lettuce
Pimenta

jalapeño

(Capsicum аппиит

L.) $\mathrm{E}$ cebola

(Allium

cepa L.)

Manga

Vermicompo st, Bokashi, Gallinaza e estatutos de adubação de manga

espéci

e

volvi

mento Análise de produção e da crescimento espéci e

Manga

volvi

Medidas

as

concentrações foliares de da $\mathrm{N}, \mathrm{K}, \mathrm{Ca}, \mathrm{Mg}, \mathrm{Zn}, \mathrm{Fe}$, espéci $\mathrm{Mn}$ e $\mathrm{Cu}$

e
Bokashi

Adiçã o de EM

Atributos de fertilidade foram avaliados: $\mathrm{ph}, \mathrm{Ca} 2$ ,$+ \mathrm{Mg} 2+, \mathrm{K}+, \mathrm{Na}+, \mathrm{P}$, $\mathrm{SB}, \mathrm{H}+\mathrm{Al}, \mathrm{CEC}$ e $\mathrm{V}$. Carbono orgânico particulado (POC) e carbono orgânico associado a minerais (MOC) e carbono orgânico total (TOC)

Proteína de soro, farelo de algodão e

Desen volvi

Alface cavaco de madeira triturada compostada e mento da

Análise de crescimento espéci e torta de crambe

Saldaña \& The influence of Hernández , et al, organic fertilizers on Alpinia purpurata

Vermicompo 2014 chemical properties of soil and
(Vieill.) K.Schum. fermentado, Bokashi, concentrações de C orgânico, $\mathrm{N}$ total, $\mathrm{P}$ 


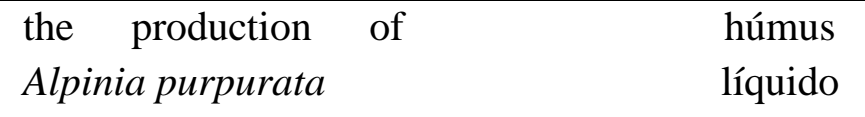

Response to organic

Peralta- fertilization in mango Antonio et cultivars: Manila, al, 2014 Tommy Atkins and Ataulfo

Effect of different Mponya et al, 2014 organic manures on yield and nutrient uptake by maize (Zea mays L.)

Enzymatic Activities in Soil Cultivated with

Gómez- Coffee (Coffea Velasco et arabica L. Cv. al, 2014 'Bourbon') and Amended with Organic Material

Effect of compost and slow-release fertilizers Bautista- addition on soil Cruz et al, biochemistry and 2014 yield of maize (Zea mays L.) In Oaaca, Mexico

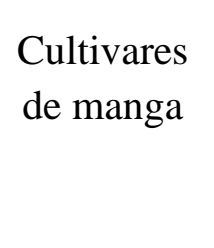

Vermicompo sto, bokashi e esterco de galinha

Desen

volvi

mento

espéci

Milho

Vermicompo
sto

Coffea Composto, arabica $\mathrm{L}$. vermicompos $\mathrm{Cv}$. Bourbon to

volvi

mento Peso fresco de raiz e

Fertilizantes

Milho de liberação lenta (srfs) e sua aplicação combinada da

e

Desen

volvi

mento

da

espéci

e

Desen da brotos, análise de solo espéci

$\mathrm{e}$

Adub

disponível e $\mathrm{K}$ trocável. Para a folhagem, os teores de $\mathrm{N}, \mathrm{P}$ e $\mathrm{K}$ foram determinados. Para o coto, determinou-se o número de hastes, a biomassa comercial e não comercial. Para o caule, comprimento, diâmetro, diâmetro da flor e comprimento da flor foram determinados.

$\mathrm{pH}, \mathrm{MO}, \quad$ macro e micronutrientes),

diâmetro de tronco, florescimento e produtividade

Altura da planta, teor de clorofila, índice de área foliar e peso seco

OS

mais Análise de solo, elulase, coloni ácido (acp) e fosfatases zação alcalinas (alp) e micor rendimento rízica (MC)

Roldi et al, Use of organic Tomate Fertilizante Adub Análise de altura, massa 
Research, Society and Development, v. 9, n. 10, e279108339, 2020

(CC BY 4.0) | ISSN 2525-3409 | DOI: http://dx.doi.org/10.33448/rsd-v9i10.8339

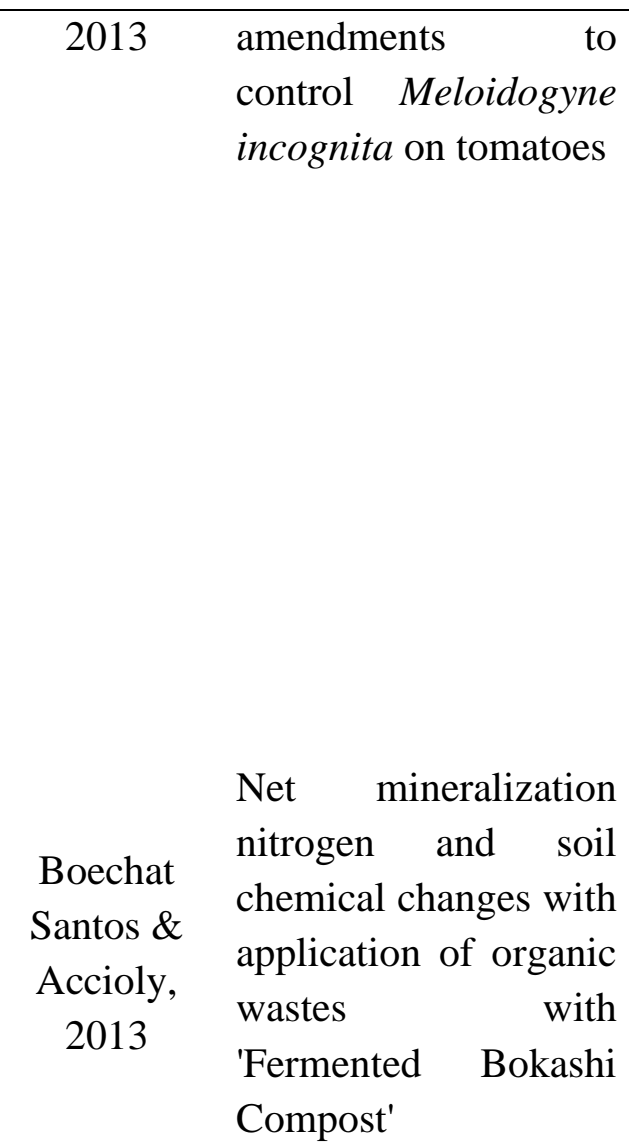

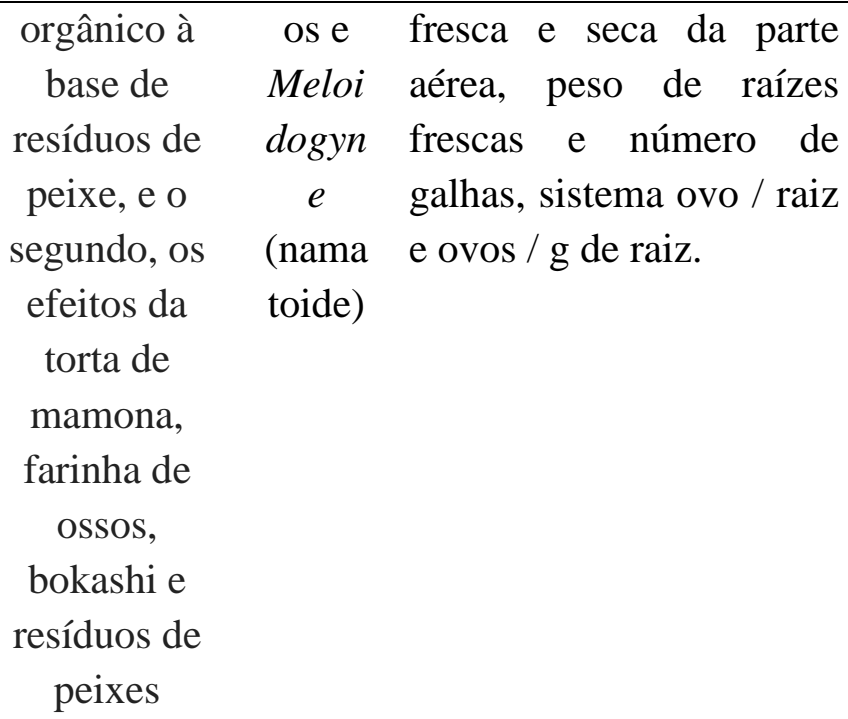

Aceves \&

Rodríguez

-Vázquez, 2013

Effects of organic amendments on the mobility of $\mathrm{Pb}$ and $\mathrm{Zn}$ from mine tailings added to semi-arid soils

Effective microorganisms' (EM): An Ndona et effective plant al, 2011 strengthening agent for tomatoes in protected cultivation

Fernandes et al, 2011
Survival and growth of eucalypts clones
Mudas de Eucalipto
Rejeitos de minas e três adubações orgânicas

compostage

$\mathrm{m}$, bokashi e vermicompos

to)

\section{A água de} irrigação foi

alterada com ema® e as plantas foram Água tratadas com e EM suspensão de pó EM-stone, farelo de trigo

Solos agríco las Evolução de CO2-C, semi- atividade inorgânica de áridos N, desidrogenase e e porcentagem pastos mobilidade de $\mathrm{Pb}$ e $\mathrm{Z}$ de

Biomassa, rendimento total, número de frutos, análise mineral de folhas 
seedlings in response

to organic fertilizer

application

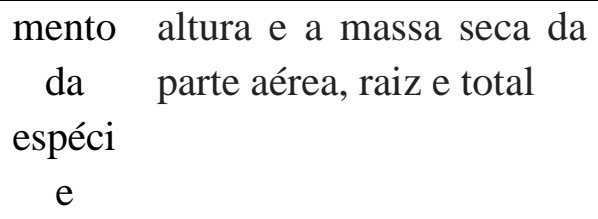

$\mathrm{e}$

\section{EM}

nos

níveis

Esatu, Effect of effective microorganisms on Melesse \& growth parameters Dessie, 2011 and serum cholesterol levels in broilers

Effect of Bokashi on Zaman, plant growth, yield Ahmed \& and essential oil quantity and quality in 2010 Patchouli

(Pogostemon cablin Benth.)

Patchouli

(Pogostem on cablin

Benth.)

Organic fertilizer as Ourives et phosphorus supplier al, 2010 for Brachiaria brizantha cv. Marandú

How effective are 'Effective

Mayer et microorganisms () al, 2010 (EM)'? Results from a field study in temperate climate

\section{Brachiaria} brizantha (A.Rich.) Stapf cv. Marandú

\section{Fertilizante} químico
Adub Análise de solo e matéria os seca
Rendimentos das culturas em cada ano e os parâmetros

microbiológicos do solo Bokas respiração do solo, Bokashi hi biomassa microbiana mais (SIR, CFE), atividade EM desidrogenase e estrutura da comunidade microbiana (RISA, CLSU), Potencial de mineralização de $\mathrm{N}$ e mineralização de $\mathrm{N}$ do 
substrato adicionado

Cyanobacteria blooms

Lurling

Tolman \&

Van

Oosterhou

t, 2010 cannot be controlled by Effective

Microorganisms

(EM®) from mud- or Bokashi-balls
Integrated

Álvarez- management of

Solís et al, inorganic and organic 2010 fertilizers in maize cropping

Shingo \& Collard greens yield Ventura, with mineral and 2009 organic fertilization

Production of

Hafle et al, seedlings of papaya 2009 tree using bokashi and lithothamnium

Cupric fungicides, benzalconium

Rezende, chlorides and liquid Tomita \& bioactive compost Uesugi, 2008 (Bokashi): Phytotoxicity and control of guava bacterial blight caused by Erwinia psidii

Pérez, Physical, chemical Céspedes and biological \& Núñez, characterization of 2008 applied organic amendments in crop
Bokas

Bokashi

hi DBO, análise de mais cianobactérias

EM

Desen

Adubos volvi

inorgânicos mento Análise de solo e análise (NP) e humos da de rendimento de grão de minhoca espéci $\mathrm{e}$
Substrato comercial para plântula e NPK

Mamona

Substrato utilizado foi uma mistura de solo, areia e composto orgânico

Fungicidas

Goiabeira cúpricos, cloretos de benzalcônio
Couve
Fitoto Fitotoxicidade foi xicida avaliada em botões de e florais e três estágios de adubo desenvolvimento de $\mathrm{s}$ frutos; a incidência da doença.
Bokashi Solo Análise de solo 
production

Dominican Republic

The effect of three

Daiss et al, organic pre-harvest 2008 treatments on Swiss chard (Beta vulgaris L. Var. Cycla L.) Quality

\section{Changes}

in

Daiss, postharvest quality of Lobo \& swiss chard grown Gonzalez, using 3 organic 2008 preharvest treatments

Formowitz et al, 2007

Vetayasup orn, 2006

Effects of biological and chemical fertiliser on growth and yield of glutinous corn production

Pei-Sheng Influence of EM \& HuiLian, 2002 bokashi on nodulation, physiological characters and yield of peanut in nature

\section{Acelga \\ (Beta} vulgaris $\mathrm{L}$. Var. Cycla

L.)

\section{Acelga}

Solo auxiliar

\section{Desen}

volvi

mento

da

espéci

e

\section{Bokashi}

produzido

com água

Banana
(Musa
ssp.)

(W), com

melaço (M)

como um

aditivo EM, e

com EM

esterilizado

(emst).

Desen

volvi

Fertilizante mento

Milho químico NPK

da
espéci e

Amendoi $\mathrm{m}$

(Arachis hypogaea
Fertilizante químico
Desen volvi mento

da espéci
Bokas Análise de EM seca e análise por HPLC
Altura da planta, o diâmetro da planta e a área das folhas, produção de espigas
Contagem de número de nódulos por planta quanto o peso fresco por nódulo, análise de fotossíntese, taxa de transpiração e 
farming fields

L.)

e

condutância do mesofilo, crescimento vegetativo e reprodutivo, pesos secos da parte aérea e da raiz

Properties and

applications of an

Yamada \& organic fertilizer

$\mathrm{Xu}, 2000$ inoculated with

effective

microorganisms

Modeling

photosynthesis decline

$\mathrm{Xu}$, Wang of excised leaves of

\& Wang, sweet corn plants

2000 grown with organic

and chemical

fertilization

Effects of organic

fertilizers and a

$\mathrm{Xu}$, Wang microbial inoculant on

\& Mridha, leaf photosynthesis

2000 and fruit yield and

quality of tomato

plants

\section{Bokas Métodos de estimativa de Bokashi hi e qualidade, produtividade EM das culturas, análise de adubo.}

Taxa

Fertilizante de fotoss íntese

Taxas fotossintéticas líquidas $(\mathrm{P} N)$, medidas usando o sistema de troca gasosa LI-6400.

Fonte: Autores (2019).

Em relação aos estudas na área de agricultura e ciências biológicas, é possível observar que de 47 artigos publicados, 12 documentos (Resman et al, 2018; Shin et al, 2017; Hanafiah et al, 2017; Ferreira et al, 2017; Lima et al, 2015; Esatu, Melesse \& Dessie, 2011; Zaman, Ahmed \& Gogoi, 2010; Mayer et al, 2010; Lurling, Tolman \& Van Osterhout, 2010; Pérez, Céspedes \& Núñez, 2008; Formowitz et al, 2007 e Yamada \& Xu, 2000) tem como foco maior apenas testar o bokashi como composto orgânico sem associação com os adubos, seja orgânico ou não.

Como exemplo, podemos citar o mais atual estudo feito por Resman et al. (2018), que teve como objetivo conhecer apenas o efeito do adubo bokashi no crescimento e produção de milho, sob tratamento de casa de vegetação, utilizando argissolo vermelho amarelo. Os resultados mostraram que a aplicação de fertilizante bokashi $(300 \mathrm{~g})$ proporcionou o melhor 
resultado para o crescimento e rendimento do milho local da Ilha de Muna.

Também podemos comentar o primeiro estudo testando o adubo com Yamada \& Xu (2000), onde pesquisas foram conduzidas para elucidar as propriedades químicas, físicas e microbiológicas do fertilizante orgânico que foi inoculado e fermentado com microrganismos (Effective Microorganisms ou EM), resultando em efeitos benéficos do fertilizante orgânico fermentado (bokashi) na fertilidade do solo e no crescimento das culturas que provavelmente dependem da fração orgânica, dos efeitos diretos dos micro-organismos introduzidos e dos efeitos indiretos dos metabólitos sintetizados por microrganismos (por exemplo, fitohormônios e reguladores de crescimento).

Em relação ao foco principal destes estudos, 17 artigos (Hoshino et al, 2016; França et al, 2016; Baldotto \& Baldotto, 2016; Álvarez-Solís et al, 2016; Peralta-Antonio et al, 2015; Dias-Arieira et al, 2015; Peralta-Antonio et al, 2014; Mponya et al, 2014; Gómez-Velasco et al, 2014; Fernandes et al, 2011; Álvarez-Solís et al, 2010; Hafle et al, 2009; Daiss et al, 2008; Daiss, Lobo \& Gonzalez, 2008; Vetayasuporn, 2006; Pei-Sheng \& Hui-Lian, 2002 e Xu, Wang, \& Mridha, 2000) tinham como interesse investigar o desenvolvimento e comportamento da planta na presença do adubo ou em associação com outros. Neste contexto temos, Hoshino et al. (2016), que buscando avaliar a influência de fertilizantes minerais e orgânicos e suas combinações no crescimento da orquídea Cattlianthe J.M.H. Shaw, concluiu que a combinação de fertilização mineral e orgânica favoreceu o crescimento de plantas híbridas.

$\mathrm{Na}$ Tabela 5, são apresentados os artigos com foco em pesquisas da área de ciência ambiental, as espécies estudadas os adubos trabalhados, qual foi o direcionamento (foco) dado pelo autor na pesquisa e a metodologia utilizada.

Tabela 5. Artigos de pesquisas com foco em Ciência Ambiental.

\section{Ciência Ambiental}

\begin{tabular}{|c|c|c|c|c|c|}
\hline Autor & Título & $\begin{array}{l}\text { Espécies } \\
\text { estudadas }\end{array}$ & $\begin{array}{l}\text { Tipo de } \\
\text { adubo }\end{array}$ & Foco & Metodologia \\
\hline \multirow[t]{2}{*}{$\begin{array}{l}\text { Urra et al, } \\
2019\end{array}$} & $\begin{array}{l}\text { The application } \\
\text { of fresh and } \\
\text { composted horse } \\
\text { and chicken }\end{array}$ & \multirow[t]{2}{*}{ Alface } & \multirow{2}{*}{$\begin{array}{l}\text { Aves: } \\
\text { esterco seco } \\
\text { e } \\
\text { compostado } \\
\text {, bokashi }\end{array}$} & \multirow[t]{2}{*}{ Solo } & \multirow{2}{*}{$\begin{array}{l}\text { Alterações nas propriedades } \\
\text { microbianas do solo, risco de } \\
\text { disseminação de antibióticos } \\
\text { Genes de resistência (args) } \\
\text { através da transferência }\end{array}$} \\
\hline & $\begin{array}{l}\text { manure affects } \\
\text { Soil quality, }\end{array}$ & & & & \\
\hline
\end{tabular}




\begin{tabular}{|c|c|c|c|c|c|}
\hline & $\begin{array}{l}\text { microbial } \\
\text { composition and } \\
\text { antibiotic } \\
\text { resistance }\end{array}$ & & & & horizontal de genes (HGT). \\
\hline $\begin{array}{l}\text { Siregar, } \\
2018\end{array}$ & $\begin{array}{l}\text { Characteristic of } \\
\text { husk charcoal, } \\
\text { bokashi compost, } \\
\text { and wood } \\
\text { charcoal as } \\
\text { biofilter filler on } \\
\text { application of } \\
\text { Ammonia } \\
\text { Percent }\end{array}$ & - & $\begin{array}{l}\text { Casca de } \\
\text { carvão e } \\
\text { carvão de } \\
\text { madeira }\end{array}$ & $\begin{array}{l}\text { Teste } \\
\text { físico }\end{array}$ & $\begin{array}{l}\text { Teor de água e densidade, } \\
\text { porosidade, quedas de pressão, } \\
\text { capacidade de retenção de água } \\
\text { (WHC), capacidade de } \\
\text { retenção de poluentes (PHC). }\end{array}$ \\
\hline $\begin{array}{l}\text { Nikitin et } \\
\text { al, } 2018\end{array}$ & $\begin{array}{l}\text { Impact of } \\
\text { effective } \\
\text { microorganisms } \\
\text { on the transfer of } \\
\text { radioactive } \\
\text { cesium into } \\
\text { lettuce and } \\
\text { barley biomass }\end{array}$ & $\begin{array}{l}\text { Alface e } \\
\text { cevada }\end{array}$ & $\begin{array}{l}\text { Combinaçã } \\
\text { o de EM } \\
\text { com } \\
\text { bokashi ou } \\
\text { fertilizante } \\
\text { de potássio }\end{array}$ & $\begin{array}{l}\text { Micror } \\
\text { ganism } \\
\text { os } \\
\text { efetivos } \\
(\text { EM) }\end{array}$ & Análise de solo \\
\hline $\begin{array}{l}\text { Castro, et } \\
\text { al, } 2018\end{array}$ & $\begin{array}{l}\text { The effects of } \\
\text { Gliricidia- } \\
\text { derived biochar } \\
\text { on sequential } \\
\text { maize and bean } \\
\text { farming }\end{array}$ & $\begin{array}{l}\text { Milho e } \\
\text { feijão }\end{array}$ & $\begin{array}{l}\text { Biocarvão } \\
\text { produzido a } \\
\text { partir de } \\
\text { Gliricidia } \\
\text { sepium } \\
\text { (Jacq.) }\end{array}$ & $\begin{array}{l}\text { Solo } \\
\text { mais } \\
\text { Azospir } \\
\text { illum } \\
\text { brasile } \\
\text { nse } \\
\text { Tarrand } \\
\text {, Krieg } \\
\& \\
\text { Döberei } \\
\text { ner, } \\
\text { 1978 } \\
\text { bokashi }\end{array}$ & $\begin{array}{l}\text { Análise do solo e de } \\
\text { produtividade de milho e feijão }\end{array}$ \\
\hline $\begin{array}{l}\text { Pérez- } \\
\text { Godínez et } \\
\text { al, } 2017\end{array}$ & $\begin{array}{l}\text { Growth and } \\
\text { reproductive } \\
\text { potential of } \\
\text { Eisenia foetida } \\
\text { (Sav) on various } \\
\text { zoo animal } \\
\text { dungs after two }\end{array}$ & & $\begin{array}{l}\text { Compostag } \\
\text { em } \\
\text { tradicional } \\
\text { e pré- } \\
\text { compostage } \\
\text { m de }\end{array}$ & Adubos & $\begin{array}{l}\text { Permanência (pef) e o potencial } \\
\text { reprodutivo (RP) de Eisenia } \\
\text { foetida, bem como a qualidade } \\
\text { do vermicomposto. }\end{array}$ \\
\hline
\end{tabular}




\begin{tabular}{|c|c|c|c|c|c|}
\hline & $\begin{array}{l}\text { methods of pre- } \\
\text { composting } \\
\text { followed by } \\
\text { vermicomposting }\end{array}$ & & bokashi & & \\
\hline $\begin{array}{l}\text { Morales et } \\
\text { al, } 2016\end{array}$ & $\begin{array}{l}\text { Effect of silicon } \\
\text { in Taro crop } \\
\text { (Colocasia } \\
\text { esculenta) in } \\
\text { combination } \\
\text { with two levels } \\
\text { of organic matter }\end{array}$ & $\begin{array}{l}\text { Batata taro } \\
\text { (Colocasia } \\
\text { esculenta } \\
\text { (L.) } \\
\text { Schott) }\end{array}$ & $\begin{array}{l}\text { Doses de } \\
\text { silício }\end{array}$ & $\begin{array}{l}\text { Aument } \\
\text { o de } \\
\text { produti } \\
\text { vidade }\end{array}$ & $\begin{array}{l}\text { Análise físicas, químicas e } \\
\text { biológicas do solo e análises de } \\
\text { rendimento }\end{array}$ \\
\hline $\begin{array}{l}\text { Jaramillo- } \\
\text { López, } \\
\text { Ramírez \& } \\
\text { Pérez- } \\
\text { Salicrup, } \\
2015\end{array}$ & $\begin{array}{l}\text { Impacts of } \\
\text { Bokashi on } \\
\text { survival and } \\
\text { growth rates of } \\
\text { Pinus } \\
\text { pseudostrobus in } \\
\text { community } \\
\text { reforestation } \\
\text { projects }\end{array}$ & - & Bokashi & $\begin{array}{l}\text { Desenv } \\
\text { olvime } \\
\text { nto da } \\
\text { espécie }\end{array}$ & Relato de caso \\
\hline $\begin{array}{l}\text { Mponya et } \\
\text { al, } 2014\end{array}$ & $\begin{array}{l}\text { Effect of } \\
\text { different organic } \\
\text { manures on yield } \\
\text { and nutrient } \\
\text { uptake by maize } \\
\text { (Zea mays L.) }\end{array}$ & Milho & $\begin{array}{l}\text { Vermicomp } \\
\text { osto }\end{array}$ & $\begin{array}{l}\text { Desenv } \\
\text { olvime } \\
\text { nto da } \\
\text { espécie }\end{array}$ & $\begin{array}{l}\text { Altura da planta, teor de } \\
\text { clorofila, índice de área foliar e } \\
\text { peso seco }\end{array}$ \\
\hline $\begin{array}{l}\text { Barajas- } \\
\text { Aceves \& } \\
\text { Rodríguez- } \\
\text { Vázquez, } \\
2013\end{array}$ & $\begin{array}{l}\text { Effects of } \\
\text { organic } \\
\text { amendments on } \\
\text { the mobility of } \\
\mathrm{Pb} \text { and } \mathrm{Zn} \text { from } \\
\text { mine tailings } \\
\text { added to semi- } \\
\text { arid soils }\end{array}$ & & $\begin{array}{l}\text { Rejeitos de } \\
\text { minas e três } \\
\text { adubações } \\
\text { orgânicas } \\
\text { (compostag } \\
\text { em, bokashi } \\
\text { e } \\
\text { vermicomp } \\
\text { osto) }\end{array}$ & $\begin{array}{l}\text { Solos } \\
\text { agrícola } \\
\text { s semi- } \\
\text { áridos e } \\
\text { pastos }\end{array}$ & $\begin{array}{l}\text { Evolução de } \mathrm{CO} 2-\mathrm{C} \text {, atividade } \\
\text { inorgânica de } \mathrm{N} \text {, desidrogenase } \\
\text { e porcentagem de mobilidade } \\
\text { de } \mathrm{Pb} \text { e } \mathrm{Zn}\end{array}$ \\
\hline $\begin{array}{l}\text { Barajas- } \\
\text { Aceves et } \\
\text { al, } 2012\end{array}$ & $\begin{array}{l}\text { Lead and zinc } \\
\text { distribution in } \\
\text { Brassica juncea } \\
\text { and arid soil } \\
\text { amended with }\end{array}$ & $\begin{array}{l}\text { Brassica } \\
\text { juncea } \\
\text { (L.) } \\
\text { Czern. }\end{array}$ & $\begin{array}{l}\text { Solo } \\
\text { alterado } \\
\text { com rejeitos } \\
\text { de mina, } \\
\text { bokashi e }\end{array}$ & $\begin{array}{l}\text { Desenv } \\
\text { olvime } \\
\text { nto da } \\
\text { espécie }\end{array}$ & $\begin{array}{l}\text { Raízes de plantas e brotações } \\
\text { foram então coletadas } \\
\text { analisadas para } \mathrm{Pb}, \mathrm{Zn}, \mathrm{Cd}, \mathrm{Cu} \\
\mathrm{Fe}, \mathrm{Hg}, \mathrm{As} \text { e } \mathrm{Sb} \text {, fracionamento } \\
\text { de } \mathrm{Pb} \text { e } \mathrm{Zn} \text {, cátions trocáveis e }\end{array}$ \\
\hline
\end{tabular}


Research, Society and Development, v. 9, n. 10, e279108339, 2020

(CC BY 4.0) | ISSN 2525-3409 | DOI: http://dx.doi.org/10.33448/rsd-v9i10.8339

\begin{tabular}{|c|c|c|c|c|c|}
\hline & $\begin{array}{l}\text { mine tailings and } \\
\text { bokashi }\end{array}$ & & $\begin{array}{l}\text { EDTA } \\
\text { (ácido } \\
\text { etilenodiam } \\
\text { inotetracétic } \\
\text { o) }\end{array}$ & & $\begin{array}{l}\text { atividades microbianas, análise } \\
\text { de solo, analise de metal } \\
\text { pesado }\end{array}$ \\
\hline $\begin{array}{l}\text { Mayer et } \\
\text { al, } 2010\end{array}$ & $\begin{array}{l}\text { How effective } \\
\text { are 'Effective } \\
\text { microorganisms } \\
\text { ® (EM)'? Results } \\
\text { from a field } \\
\text { study } \\
\text { temperate } \\
\text { climate }\end{array}$ & - & Bokashi & $\begin{array}{l}\text { Bokash } \\
\text { i mais } \\
\text { EM }\end{array}$ & $\begin{array}{l}\text { Rendimentos das culturas em } \\
\text { cada ano e os parâmetros } \\
\text { microbiológicos do solo } \\
\text { respiração do solo, biomassa } \\
\text { microbiana (SIR, CFE), } \\
\text { atividade desidrogenase e } \\
\text { estrutura da comunidade } \\
\text { microbiana (RISA, CLSU), } \\
\text { Potencial de mineralização de } \\
\mathrm{N} \text { e mineralização de N do } \\
\text { substrato adicionado }\end{array}$ \\
\hline $\begin{array}{l}\text { Álvarez- } \\
\text { Solís et al, } \\
2010\end{array}$ & $\begin{array}{l}\text { Integrated } \\
\text { management of } \\
\text { inorganic and } \\
\text { organic } \\
\text { fertilizers in } \\
\text { maize cropping }\end{array}$ & Milho & $\begin{array}{l}\text { Adubos } \\
\text { inorgânicos } \\
(\mathrm{NP}) \mathrm{e} \\
\text { humos de } \\
\text { minhoca }\end{array}$ & $\begin{array}{l}\text { Desenv } \\
\text { olvime } \\
\text { nto da } \\
\text { espécie }\end{array}$ & $\begin{array}{l}\text { Análise de solo e anpalise de } \\
\text { rendimento de grão }\end{array}$ \\
\hline $\begin{array}{l}\text { Lurling, } \\
\text { Tolman \& } \\
\text { Euwe, } \\
2009\end{array}$ & $\begin{array}{l}\text { Mitigating } \\
\text { cyanobacterial } \\
\text { blooms: How } \\
\text { effective are } \\
\text { 'effective } \\
\text { microorganisms' } \\
?\end{array}$ & - & Bokashi & $\begin{array}{l}\text { Bokash } \\
\text { i mais } \\
\text { EM }\end{array}$ & $\begin{array}{l}\text { Análise de água e metal pesado } \\
\text { na água }\end{array}$ \\
\hline $\begin{array}{l}\text { Aulinas } \\
\text { Masó, \& } \\
\text { Bonmatí } \\
\text { Blasi, 2008 }\end{array}$ & $\begin{array}{l}\text { Evaluation of } \\
\text { composting as a } \\
\text { strategy for } \\
\text { managing } \\
\text { organic wastes } \\
\text { from a municipal } \\
\text { market in } \\
\text { Nicaragua }\end{array}$ & - & $\begin{array}{l}\text { Compostag } \\
\text { em, } \\
\text { compostage } \\
\text { m com } \\
\text { resíduos de } \\
\text { quintal, } \\
\text { bokashi e } \\
\text { vermicomp } \\
\text { osto }\end{array}$ & $\begin{array}{l}\text { Fluxo } \\
\text { de } \\
\text { resíduo } \\
\mathrm{s} \\
\text { sólidos } \\
\text { urbanos } \\
\text { (RSU) }\end{array}$ & $\begin{array}{l}\text { Observação do uso de resíduos } \\
\text { de supermercado }\end{array}$ \\
\hline
\end{tabular}

Fonte: Autores (2019). 
Research, Society and Development, v. 9, n. 10, e279108339, 2020

(CC BY 4.0) | ISSN 2525-3409 | DOI: http://dx.doi.org/10.33448/rsd-v9i10.8339

Dos 14 artigos investigados, 7 estudos (Siregar, 2018; Pérez-Godínez et al, 2017; Jaramillo-López, Ramírez \& Pérez-Salicrup, 2015; Barajas-Aceves \& Rodríguez-Vázquez, 2013; Mayer et al, 2010; Lurling, Tolman \& Euwe, 2009 e Aulinas Masó \& Bonmatí Blasi, 2008) não avaliaram o adubo bokashi ou sua associação com outros fertilizantes, em função da resposta observada em plantas, mas sim focaram em entender apenas o adubo. Como é o caso de Pérez-Godínez et al. (2017), que em estudos de crescimento e potencial reprodutivo de Eisenia foetida (Sav) em vários animais do zoológico, constatou que é necessário estudos com plantas são necessários para avaliar os benefícios e limitações destes métodos de précompostagem antes da vermicompostagem.

Na Tabela 6 é apresentada a relação dos 9 artigos com estudos apenas na área de bioquímica, genética e biologia molecular, na tabela é possível observar as espécies estudadas, os tipos de adubos utilizados, qual foi o direcionamento (foco) dado pelo autor na pesquisa e a metodologia empregada.

Tabela 6. Artigos de pesquisas com foco em bioquímica, genética e biologia molecular.

\section{Bioquímica, Genética e Biologia Molecular}

\begin{tabular}{|c|c|c|c|c|c|}
\hline Autor & Título & $\begin{array}{c}\text { Espécies } \\
\text { estudadas }\end{array}$ & $\begin{array}{l}\text { Tipo de } \\
\text { adubo }\end{array}$ & Foco & Metodologia \\
\hline $\begin{array}{l}\text { Laskows } \\
\text { ka,Jarosz } \\
\& \\
\text { Grądzki, } \\
2019\end{array}$ & $\begin{array}{l}\text { Effect of Multi-Microbial } \\
\text { Probiotic Formulation } \\
\text { Bokashi on Pro- and Anti- } \\
\text { Inflammatory Cytokines } \\
\text { Profile in the Serum, } \\
\text { Colostrum and Milk of } \\
\text { Sows, and in a Culture of } \\
\text { Polymorphonuclear Cells } \\
\text { Isolated from Colostrum }\end{array}$ & Suínos & Bokashi & $\begin{array}{l}\text { Sangue } \\
\text { periféric } \\
\text { o, } \\
\text { colostro } \\
\text { e leite. }\end{array}$ & $\begin{array}{l}\text { Análises de sangue e de } \\
\text { colostro }\end{array}$ \\
\hline $\begin{array}{l}\text { Siregar, } \\
2018\end{array}$ & $\begin{array}{l}\text { Characteristic of husk } \\
\text { charcoal, bokashi } \\
\text { compost, and wood } \\
\text { charcoal as biofilter filler } \\
\text { on application of } \\
\text { Ammonia } 5 \text { Percent }\end{array}$ & - & $\begin{array}{l}\text { Casca de } \\
\text { carvão e } \\
\text { carvão de } \\
\text { madeira }\end{array}$ & $\begin{array}{l}\text { Teste } \\
\text { físico }\end{array}$ & $\begin{array}{l}\text { Teor de água e } \\
\text { densidade, porosidade, } \\
\text { quedas de pressão, } \\
\text { capacidade de retenção } \\
\text { de água (WHC), } \\
\text { capacidade de retenção } \\
\text { de poluentes (PHC). }\end{array}$ \\
\hline $\begin{array}{l}\text { Morales } \\
\text { et al, }\end{array}$ & $\begin{array}{l}\text { Effect of silicon in Taro } \\
\text { crop (Colocasia esculenta) } \\
\text { in combination with two }\end{array}$ & $\begin{array}{l}\text { Batata taro } \\
\text { (Colocasia }\end{array}$ & $\begin{array}{l}\text { Doses de } \\
\text { silício }\end{array}$ & $\begin{array}{l}\text { Aumento } \\
\text { de } \\
\text { produtivi }\end{array}$ & $\begin{array}{l}\text { Análise físicas, } \\
\text { químicas e biológicas } \\
\text { do solo e análises de }\end{array}$ \\
\hline
\end{tabular}


$2016 \quad$ levels of organic matter

Barajas-

Aceves et

al., 2012

Lead and zinc distribution

in Brassica juncea and

arid soil amended with

mine tailings and bokashi

Effect of microaerobic

Alattar et fermentation in

al, 2012 preprocessing fibrous

lignocellulosic materials

Zaman,

Ahmed

\& Gogoi,

2010

Effect of Bokashi on plant growth, yield and essential oil quantity and quality in Patchouli (Pogostemon cablin Benth.)

Yamada

Properties and

$\& \mathrm{Xu}$, applications of an organic 2000

$\mathrm{Xu}$, fertilizer inoculated with effective microorganisms

Wang \&

Wang, 2000

Modeling photosynthesis decline of excised leaves of sweet corn plants grown with organic and chemical fertilization

$\mathrm{Xu}, \quad$ Effects of organic

Wang \& fertilizers and a microbial Mridha, inoculant on leaf $2000 \quad$ photosynthesis and fruit yield and quality of
Patchouli

(Pogostem on cablin

Benth.)

Bokashi

Bokashi
e EM

Fertilizant e químico

Taxa de fotossínt ese

Desenvol

Esterco de vimento galinha da espécie óleo essencial mais bokashi
Raízes de plantas e brotações foram então coletadas e analisadas para $\mathrm{Pb}, \mathrm{Zn}, \mathrm{Cd}, \mathrm{Cu}, \mathrm{Fe}$, $\mathrm{Hg}$, As e Sb, fracionamento de $\mathrm{Pb}$ e Zn, cátions trocáveis e atividades microbianas, análise de solo, analise de metal pesado

Teor de

Altura máxima, número de ramos, tamanho da folha e índice de área foliar, teor de óleo essencial e extração de óleo e análise de GC

Métodos de estimativa de qualidade, produtividade das culturas, análise de adubo

Taxas fotossintéticas líquidas (P N), medidas usando o sistema de troca gasosa LI-6400

Fotossíntese e rendimento de frutos e qualidade de plantas 
tomato plants

Fonte: Autores (2019).

Em estudos relacionados a área de bioquímica, genética e biologia molecular, podemos observar que em se tratando das espécies estudadas não apenas vegetais foram pesquisados mas também suínos, onde Laskowska, Jarosz \& Grądzki, Z. (2019) com o objetivo de determinar o efeito da formulação de bokashi sobre as concentrações de citocinas pró e anti-inflamatórias no soro de 60 porcas durante a gravidez, no colostro e no leite e em uma cultura de células polimorfonucleares estimuladas por Con-A. (PMNs) isolados do colostro. Observou que ao mesmo tempo, o aumento das concentrações de citocinas IL-4, IL10 , TGF- $\beta$ e de imunoglobulinas no colostro e no leite de porcas no grupo experimental demonstra o efeito imunorregulatório do bokashi nas células Th2 e pode levar ao aumento da expressão de células T reguladoras e polarização da resposta imune de Th1 a Th2.

Nota-se que em estudos desta área existe também a adubação com bokashi enriquecido com silício, onde o efeito da aplicação de dois níveis de matéria orgânica em combinação com quatro doses de silício ( $5 \mathrm{~kg} / \mathrm{ha}, 10 \mathrm{~kg} / \mathrm{ha}, 15 \mathrm{~kg} / \mathrm{ha}$ e $20 \mathrm{~kg} / \mathrm{ha}$ ), no cultivo de taro na província de Pastaza no Equador; onde os tratamentos com adubação orgânica e silício, obtiveram rendimento médio de 18,77 t / ha, equivalente a 5,65 vezes ou 565,4\% superior ao controle. Isso indica uma enorme diferença no rendimento como resultado da matéria orgânica, que influenciou na quantidade e qualidade do produto. Além disso, este tratamento mostra benefícios físicos, químicos e biológicos às propriedades do solo. Nota-se que o uso do bokashi associado com o acréscimo de silício aumentou a produção de batata taro (Colocasia esculenta (L.) Schott - Araceae), foi o que observou Morales, E. B. (2016) e seus colaboradores. O mesmo pode ser observado na área de imunologia e microbiologia, onde estes mesmos artigos (Laskowska, Jarosz \& Grądzki, 2019 e Morales et al., 2016), também foram enquadrados, conforme segue na Tabela 7.

Tabela 7. Artigos de pesquisas com foco em imunologia e microbiologia.

\section{Imunologia e Microbiologia}

\begin{tabular}{lccccc}
\hline Autor & Título & $\begin{array}{c}\text { Espécies } \\
\text { estudada } \\
\text { s }\end{array}$ & $\begin{array}{c}\text { Tipo de } \\
\text { adubo }\end{array}$ & Foco & Metodologia \\
\hline Laskows & Effect of Multi-Microbial & Suínos & Bokashi & Sangue & Análises de \\
\hline
\end{tabular}




\begin{tabular}{cc}
\hline ka, Jarosz & Probiotic Formulation \\
$\&$ & Bokashi on Pro- and Anti- \\
Grądzki, & Inflammatory Cytokines \\
2019 & Profile in the Serum, \\
& Colostrum and Milk of \\
& Sows, and in a Culture of \\
& Polymorphonuclear Cells \\
& Isolated from Colostrum
\end{tabular}

Morales

et al,

2016

\section{Kale \& Sustainable treatment of} Anthappa wastewater using

n, 2012 effective microorganisms

$\begin{array}{cc}\text { Alattar et } & \text { fermentation in } \\ \text { al, 2012 } & \begin{array}{c}\text { preprocessing fibrous } \\ \text { lignocellulosic materials }\end{array}\end{array}$

Yamada $\& \mathrm{Xu}$, 2000

$\mathrm{Xu}$, Wang \& Wang, 2000

Modeling photosynthesis Properties and applications of an organic fertilizer inoculated with effective microorganisms decline of excised leaves of sweet corn plants grown with organic and chemical fertilization periférico,

colostro e

leite.

\section{sangue e de colostro}

\author{
Batata \\ taro \\ (Colocasi \\ a \\ esculenta) \\ Doses de \\ silício \\ Aumento de \\ produtividade
}

Bokashi

Bokashi e EM

Bokashi,

Materiais

orgânicos

fibrosos

lignocelul

ósicos

(FLC)

Análise físicas, químicas e biológicas do solo e análises de rendimento

Tecnologia

Efetiva de

Micro-

organismos (EM

- Technology)

Fragmentação de PS e a produção de metabólitos e gases solúveis

Bokashi Bokashi e EM

Métodos de estimativa de qualidade, produtividade das culturas, análise de adubo

Taxas fotossintéticas líquidas (P N), medidas usando o sistema de troca gasosa LI6400
$\mathrm{Xu}$,
Effects of organic 
Research, Society and Development, v. 9, n. 10, e279108339, 2020

(CC BY 4.0) | ISSN 2525-3409 | DOI: http://dx.doi.org/10.33448/rsd-v9i10.8339

\begin{tabular}{|c|c|c|c|c|c|}
\hline $\begin{array}{c}\text { Wang \& } \\
\text { Mridha, } \\
2000\end{array}$ & $\begin{array}{l}\text { fertilizers and a microbial } \\
\text { inoculant on leaf } \\
\text { photosynthesis and fruit } \\
\text { yield and quality of } \\
\text { tomato plants }\end{array}$ & & $\begin{array}{c}\text { de } \\
\text { galinha }\end{array}$ & nto da espécie & $\begin{array}{l}\text { rendimento de } \\
\text { frutos e } \\
\text { qualidade de } \\
\text { plantas }\end{array}$ \\
\hline $\begin{array}{c}\text { Goyal, et } \\
\text { al, } 1999\end{array}$ & $\begin{array}{l}\text { Effect of anaerobically } \\
\text { fermented manure on the } \\
\text { soil organic matter, } \\
\text { microbial properties and } \\
\text { growth of Spinach under } \\
\text { greenhouse conditions }\end{array}$ & Espinafre & $\begin{array}{c}\text { Fertilizan } \\
\text { te } \\
\text { químico }\end{array}$ & $\begin{array}{l}\text { Desenvolvime } \\
\text { nto da espécie }\end{array}$ & $\begin{array}{c}\text { Matéria orgânica } \\
\text { do solo, a } \\
\text { biomassa } \\
\text { microbiana, a } \\
\text { atividade } \\
\text { desidrogenase e } \\
\text { o crescimento de } \\
\text { espinafre }\end{array}$ \\
\hline
\end{tabular}

Fonte: Autores (2019).

Na Tabela 7 é possível observar as espécies e animais estudados, os tipos de adubos que foram empregados nas pesquisas, qual foi o direcionamento (foco) dado pelo autor no artigo e a metodologia utilizada.

Nos oito estudos de imunologia e microbiologia podemos destacar o primeiro estudo realizado e publicado cientificamente sobre bokashi, onde Goyal et al. (1999), começou suas pesquisas com espinafre. Matéria orgânica do solo, a biomassa microbiana, a atividade desidrogenase e o crescimento de espinafre foram determinados após as adições de fertilizante inorgânico, fertilizante orgânico fermentado anaerobiamente, bokashi (úmido ou seco ao ar) ou uma combinação de fertilizante inorgânico com bokashi úmido, notou que o rendimento de espinafre foi menor no tratamento com fertilizante químico sozinho e maior com bokashi úmido seguido de bokashi seco ao ar e uma combinação de fertilizante químico com bokashi. Os efeitos sobre a biomassa microbiana do solo foram semelhantes com o Bokashi úmido e seco ao ar. No entanto, o bokashi úmido deu melhor rendimento de espinafre do que o ar seco.

Na Tabela 8 é apresentada a relação dos 4 artigos com estudos na área de energia, seus respectivos títulos, espécies estudadas, tipos de adubos empregados, qual foi o direcionamento (foco) dado pelo autor na pesquisa e a metodologia utilizada. 
Tabela 8. Artigos de pesquisas com foco em energia.

\section{Energia}

\begin{tabular}{|c|c|c|c|c|c|}
\hline Autor & Título & $\begin{array}{l}\text { Espécies } \\
\text { estudadas }\end{array}$ & $\begin{array}{l}\text { Tipo de } \\
\text { adubo }\end{array}$ & Foco & Metodologia \\
\hline $\begin{array}{l}\text { Abdul Aziz, } \\
\text { Hanafiah, } \\
\text { Mohamed } \\
\text { Ali, } 2019\end{array}$ & $\begin{array}{l}\text { Sustainable biogas } \\
\text { production from } \\
\text { agrowaste and } \\
\text { effluents - A } \\
\text { promising step for } \\
\text { small-scale } \\
\text { industry income }\end{array}$ & - & $\begin{array}{l}\text { Esterco de } \\
\text { cabra, esterco } \\
\text { de galinha, } \\
\text { resíduo de } \\
\text { peixe, } \\
\text { resíduo de } \\
\text { arroz, } \\
\text { efluente de } \\
\text { lagar de } \\
\text { palma e lodo } \\
\text { de esgoto }\end{array}$ & $\begin{array}{c}\text { Produção de } \\
\text { biogás }\end{array}$ & $\begin{array}{c}\text { Características } \\
\text { físico-químicas } \\
\text { foram avaliadas por } \\
\text { análises } \\
\text { laboratoriais, } \\
\text { enquanto o ensaio } \\
\text { Bio-Methane } \\
\text { Potential (BMP) foi } \\
\text { utilizado para medir } \\
\text { a produção de biogás } \\
\text { sob condições } \\
\text { mesofílicas durante } \\
20 \text { dias consecutivos. }\end{array}$ \\
\hline $\begin{array}{l}\text { Castro, et } \\
\text { al, } 2018\end{array}$ & $\begin{array}{c}\text { The effects of } \\
\text { Gliricidia-derived } \\
\text { biochar on } \\
\text { sequential maize } \\
\text { and bean farming }\end{array}$ & $\begin{array}{l}\text { Milho e } \\
\text { feijão }\end{array}$ & $\begin{array}{l}\text { Biocarvão } \\
\text { produzido a } \\
\text { partir de } \\
\text { Gliricidia } \\
\text { sepium } \\
\text { (Jacq.) }\end{array}$ & $\begin{array}{c}\text { Solo mais } \\
\text { Azospirillu } \\
m \\
\text { brasilense e } \\
\text { bokashi }\end{array}$ & $\begin{array}{l}\text { Análise do solo e de } \\
\text { produtividade de } \\
\text { milho e feijão }\end{array}$ \\
\hline $\begin{array}{l}\text { Aulinas } \\
\text { Masó, } \\
\text { Bonmatí } \\
\text { Blasi, } 2008\end{array}$ & $\begin{array}{l}\text { Evaluation of } \\
\text { composting as a } \\
\text { strategy for } \\
\text { managing organic } \\
\text { wastes from a } \\
\text { municipal market } \\
\text { in Nicaragua }\end{array}$ & - & $\begin{array}{l}\text { Compostage } \\
\text { m, } \\
\text { compostagem } \\
\text { com resíduos } \\
\text { de quintal, } \\
\text { bokashi e } \\
\text { vermicompos } \\
\text { to }\end{array}$ & $\begin{array}{l}\text { Fluxo de } \\
\text { resíduos } \\
\text { sólidos } \\
\text { urbanos } \\
\text { (RSU) }\end{array}$ & $\begin{array}{l}\text { Observação do uso } \\
\text { de resíduos de } \\
\text { supermercado }\end{array}$ \\
\hline $\begin{array}{l}\text { Pei-Sheng, } \\
\text { \& Hui-Lian, } \\
2002\end{array}$ & $\begin{array}{l}\text { Influence of EM } \\
\text { bokashi on } \\
\text { nodulation, } \\
\text { physiological } \\
\text { characters and } \\
\text { yield of peanut in } \\
\text { nature farming } \\
\text { fields }\end{array}$ & $\begin{array}{l}\text { Amendoi } \\
\mathrm{m}\end{array}$ & $\begin{array}{l}\text { Fertilizante } \\
\text { químico }\end{array}$ & $\begin{array}{l}\text { Desenvolvi } \\
\text { mento da } \\
\text { espécie }\end{array}$ & $\begin{array}{l}\text { Contagem de } \\
\text { número de nódulos } \\
\text { por planta quanto o } \\
\text { peso fresco por } \\
\text { nódulo, análise de } \\
\text { fotossíntese, taxa de } \\
\text { transpiração e } \\
\text { condutância do } \\
\text { mesofilo, }\end{array}$ \\
\hline
\end{tabular}




\section{crescimento \\ vegetativo e reprodutivo, pesos secos da parte aérea e da raiz.}

Fonte: Autores (2019).

Dos quatro artigos pesquisados na área de energia, dois trabalharam com espécies vegetais (Castro et al, 2018 e Pei-Sheng \& Hui-Lian, 2002), destes as pesquisas foram com milho e feijão e amendoim respectivamente e dois (Abdul Aziz, Hanafiah \& Mohamed Ali , 2019 e Aulinas Masó \& Bonmatí Blasi, 2008) trabalharam com tipos de adubos diferentes, o primeiro artigo testou esterco de cabra, esterco de galinha, resíduo de peixe, resíduo de arroz, efluente de lagar de palma e lodo de esgoto e o segundo artigo compostagem, compostagem com resíduos de quintal, bokashi e vermicomposto. Onde podemos citar Pei-Sheng \& HuiLian (2002) que verificou o efeito do desenvolvimento do amendoim com fertilizante orgânico EM bokashi sobre a nodulação, propriedades fisiológicas e produtividade de plantas de amendoim foram investigados em um campo de agricultura natural, concluindo que EM bokashi é um fertilizante orgânico eficaz na produção de culturas agrícolas.

Na Tabela 9 é apresentada a relação dos 4 artigos com estudos considerados multidisciplinar, seus respectivos títulos, espécies estudadas, tipos de adubos empregados, principal foco da pesquisa e metodologia usada.

Tabela 9. Artigos de pesquisas considerados multidisciplinar.

\section{Multidisciplinar}

\begin{tabular}{|c|c|c|c|c|c|}
\hline Autor & Título & $\begin{array}{c}\text { Espécies } \\
\text { estudadas }\end{array}$ & $\begin{array}{l}\text { Tipo de } \\
\text { adubo }\end{array}$ & Foco & Metodologia \\
\hline $\begin{array}{l}\text { Ekebafe, } \\
\text { Ekebafe, } \\
\text { Ugbesia, } \\
2015\end{array}$ & $\begin{array}{l}\text { Biochar composts } \\
\text { and composites }\end{array}$ & - & Bokashi & $\begin{array}{c}\text { Documento } \\
\text { com alegações }\end{array}$ & Visão geral \\
\hline $\begin{array}{c}\text { Saldaña \& } \\
\text { Hernández et } \\
\text { al, } 2014\end{array}$ & $\begin{array}{l}\text { Effect of organic } \\
\text { fertilizers on soil } \\
\text { microbial dynamics } \\
\text { and production of } \\
\text { Alpinia purpurata }\end{array}$ & $\begin{array}{c}\text { Alpinia } \\
\text { purpurata }\end{array}$ & $\begin{array}{c}\text { Vermico } \\
\text { mpostage } \\
\text { m, esterco } \\
\text { fermentad } \\
\text { o, } \\
\text { Bokashi e }\end{array}$ & $\begin{array}{l}\text { Desenvolvime } \\
\text { nto da espécie }\end{array}$ & $\begin{array}{l}\text { Analise } \\
\text { química }\end{array}$ \\
\hline
\end{tabular}




\begin{tabular}{|c|c|c|c|c|c|}
\hline & (Vieill) K. Schum & & $\begin{array}{l}\text { húmus } \\
\text { líquido e } \\
\text { adubos } \\
\text { químicos }\end{array}$ & & \\
\hline $\begin{array}{l}\text { Karimuna, } \\
\text { Leomo \& } \\
\text { Indriyani, } \\
2012\end{array}$ & $\begin{array}{l}\text { Improvement of } \\
\text { Maize and Peanut } \\
\text { production in } \\
\text { intercropping system } \\
\text { through the } \\
\text { application of } \\
\text { organic fertilizer and } \\
\text { mulch in ultisol soil }\end{array}$ & $\begin{array}{c}\text { Milho e } \\
\text { amendoim }\end{array}$ & $\begin{array}{l}\text { Adubação } \\
\text { vegetal } \\
\text { morta e } \\
\text { bokashi } \\
\text { da } \\
\text { vegetação } \\
\text { secundári } \\
\text { a }\end{array}$ & $\begin{array}{l}\text { Desenvolvime } \\
\text { nto da espécie }\end{array}$ & $\begin{array}{c}\text { Altura da } \\
\text { planta (cm) de } \\
28 \text { e } 56 \text { dias } \\
\text { após o plantio, } \\
\text { Índice de Área } \\
\text { Foliar (IAF) de } \\
28 \text { e } 56 \text { dias } \\
\text { após o plantio, } \\
\text { diâmetro do } \\
\text { caule (cm), } \\
\text { peso seco de } \\
\text { feijão } 100 \mathrm{~g} \text { a } \\
14 \% \text { de } \\
\text { umidade e } \\
\text { semente seca } \\
\text { peso (t ha-1) }\end{array}$ \\
\hline $\begin{array}{c}\text { Borda- } \\
\text { Molina et al, } \\
2011\end{array}$ & $\begin{array}{c}\text { Influence of organic } \\
\text { matter and } \\
\text { Azotobacter } \\
\text { nigricans on a Stevia } \\
\text { rebaudiana } \mathrm{B} . \\
\text { Plantation }\end{array}$ & $\begin{array}{c}\text { Stevia } \\
\text { rebaudiana B. }\end{array}$ & $\begin{array}{c}\text { Matéria } \\
\text { orgânica e } \\
\text { de um } \\
\text { biofertiliz } \\
\text { ante } \\
\text { baseado } \\
\text { em } \\
\text { Azotobact } \\
\text { er } \\
\text { nigricans }\end{array}$ & $\begin{array}{c}\text { Adubos e } \\
\text { azobactéria }\end{array}$ & $\begin{array}{c}\text { Biomassa } \\
\text { medido em } \\
\text { peso seco, } \\
\text { produção e } \\
\text { área foliar. A } \\
\text { análise físico- } \\
\text { química do } \\
\text { solo }\end{array}$ \\
\hline
\end{tabular}

Fonte: Autores (2019).

Nos quatro estudos classificados como multidisciplinar temos o trabalho de Ekebafe, Ekebafe \& Ugbesia (2015) que com uma visão geral reuniu um documento com várias informações sobre qualidade de solo gerada pelo bokashi, onde a intenção desta visão geral é além de reunir informações sobre o assunto é também identificar lacunas no conhecimento que requerem mais pesquisas. 
Research, Society and Development, v. 9, n. 10, e279108339, 2020

(CC BY 4.0) | ISSN 2525-3409 | DOI: http://dx.doi.org/10.33448/rsd-v9i10.8339

Na Tabela 10 é apresentado a relação dos 2 artigos com estudos na área de química, seus respectivos títulos, espécies estudadas, tipos de adubos empregados, principal foco da pesquisa e metodologia usada.

Tabela 10. Artigos com estudos realizados na área de química.

\section{Química}

\begin{tabular}{|c|c|c|c|c|c|}
\hline Autor & Título & $\begin{array}{c}\text { Espécies } \\
\text { estudadas }\end{array}$ & $\begin{array}{l}\text { Tipo de } \\
\text { adubo }\end{array}$ & Foco & Metodologia \\
\hline $\begin{array}{c}\text { Nurhidayati et } \\
\text { al, } 2014\end{array}$ & $\begin{array}{l}\text { Effectiveness of } \\
\text { various mulch towards } \\
\text { chemical fertility, soil } \\
\text { erosion and crops } \\
\text { production of potato } \\
\text { (Solanum tuberosum, } \\
\text { Linn) in Andisol of } \\
\text { Ranupani, East Java }\end{array}$ & Batata & Bokashi & $\begin{array}{l}\text { Bokashi } \\
\text { mais } \\
\text { cobertura } \\
\text { morta ou } \\
\text { plástico }\end{array}$ & Análise de solo \\
\hline $\begin{array}{c}\text { Park \& Kremer, } \\
2010\end{array}$ & $\begin{array}{l}\text { Establishment of an } \\
\text { inoculated bacterial } \\
\text { strain on plant root } \\
\text { surfaces in soils with } \\
\text { different microbial } \\
\text { community }\end{array}$ & $\begin{array}{l}\text { Raízes de } \\
\text { beterraba }\end{array}$ & Bokashi & $\begin{array}{c}\text { EM- } \\
\text { Bokashi }\end{array}$ & $\begin{array}{c}\text { Análise de } \\
\text { microrganismo no } \\
\text { solo }\end{array}$ \\
\hline
\end{tabular}

Fonte: Autores (2019).

Dos dois artigos relacionados a área de química temos Nurhidayati et al. (2014) com testes para determinar a eficácia da cobertura morta relacionada às mudanças na fertilidade química, erosão e produção de batata em Andisol de Ranupani, onde por meio de analises de solo constatou que a palha de bokashi (M3) melhorou efetivamente a fertilidade química da seguinte forma: C de 9,19\%, $\mathrm{N}$ de 7,69\%, $\mathrm{P}$ de 76,01\% comparado a M0.

Park \& Kremer (2010), com o uso e aplicação de fertilizante biológico EM-Bokashi e radiação de micro-ondas, realizando análises de microrganismo no solo, concluíram que a comunidade microbiana do solo mudou devido à aplicação de um fertilizante biológico EMBokashi e radiação de micro-ondas.

Na Tabela 11 é apresentado a relação dos 2 artigos com estudos na área de ciências sociais, seus respectivos títulos, espécies estudadas, tipos de adubos empregados, principal foco da pesquisa e metodologia usada. 
Research, Society and Development, v. 9, n. 10, e279108339, 2020

(CC BY 4.0) | ISSN 2525-3409 | DOI: http://dx.doi.org/10.33448/rsd-v9i10.8339

Tabela 11. Artigos com estudos realizados na área de ciências sociais.

\section{Ciências Sociais}

\begin{tabular}{|c|c|c|c|c|c|}
\hline Autor & Título & $\begin{array}{c}\text { Espécies } \\
\text { estudadas }\end{array}$ & $\begin{array}{l}\text { Tipo de } \\
\text { adubo }\end{array}$ & Foco & Metodologia \\
\hline $\begin{array}{c}\text { Castro et al, } \\
2018\end{array}$ & $\begin{array}{l}\text { The effects of } \\
\text { Gliricidia- } \\
\text { derived biochar } \\
\text { on sequential } \\
\text { maize and bean } \\
\text { farming }\end{array}$ & $\begin{array}{l}\text { Milho e } \\
\text { feijão }\end{array}$ & $\begin{array}{l}\text { Biocarvão } \\
\text { produzido a } \\
\text { partir de } \\
\text { Gliricidia } \\
\text { sepium } \\
\text { (Jacq.) }\end{array}$ & $\begin{array}{c}\text { Solo mais } \\
\text { Azospirillu } \\
\quad m \\
\text { brasilense } \\
\text { e bokashi }\end{array}$ & $\begin{array}{l}\text { Análise do solo e de } \\
\text { produtividade de } \\
\text { milho e feijão }\end{array}$ \\
\hline $\begin{array}{l}\text { Pei-Sheng \& } \\
\text { Hui-Lian, } \\
2002\end{array}$ & $\begin{array}{l}\text { Influence of EM } \\
\text { bokashi on } \\
\text { nodulation, } \\
\text { physiological } \\
\text { characters and } \\
\text { yield of peanut } \\
\text { in nature } \\
\text { farming fields }\end{array}$ & Amendoim & $\begin{array}{c}\text { Fertilizante } \\
\text { químico }\end{array}$ & $\begin{array}{l}\text { Desenvolv } \\
\text { imento da } \\
\text { espécie }\end{array}$ & $\begin{array}{c}\text { Contagem de número } \\
\text { de nódulos por planta } \\
\text { quanto o peso fresco } \\
\text { por nódulo, análise de } \\
\text { fotossíntese, taxa de } \\
\text { transpiração e } \\
\text { condutância do } \\
\text { mesofilo, crescimento } \\
\text { vegetativo e } \\
\text { reprodutivo, pesos } \\
\text { secos da parte aérea e } \\
\text { da raiz }\end{array}$ \\
\hline
\end{tabular}

Fonte: Autores (2019).

Pei-Sheng \& Hui-Lian, X. (2002) e Castro et al. (2018) além de serem considerados estudo de ciências sócias também foram enquadrados como sendo da área de energia, como já apresentado na tabela 8 , neste contexto, como já foi relato a pesquisa realizada por Pei-Sheng \& Hui-Lian (2002), será apresentado a pesquisa de Castro et al. (2018) que testando os efeitos de biocarvão derivado da gliricídia do milho sequencial e na produção de feijão, com testes em solos mais Azospirillum brasilense e bokashi, concluindo que o biocarvão aumentou a produção de vagens e biomassa, mas o aumento significativo foi observado somente com a inoculação com Azospirillum brasilense e bokashi.

Na Tabela 12 é apresentado a relação dos 2 artigos com estudos na área de veterinária, título dos artigos, espécies estudadas, tipos de adubo, foco da pesquisa (direcionamento) e a metodologia utilizada. 
Tabela 12. Artigos com estudos realizados na área de veterinária.

\section{Veterinária}

\begin{tabular}{|c|c|c|c|c|c|}
\hline Autor & Título & $\begin{array}{l}\text { Espécies } \\
\text { estudadas }\end{array}$ & $\begin{array}{l}\text { Tipo de } \\
\text { adubo }\end{array}$ & Foco & Metodologia \\
\hline $\begin{array}{l}\text { Laskowska, } \\
\text { Jarosz \& } \\
\text { Grądzki, } \\
2017\end{array}$ & $\begin{array}{l}\text { The effect of feed } \\
\text { supplementation } \\
\text { with effective } \\
\text { microorganisms } \\
\text { (EM) on pro- and } \\
\text { anti-inflammatory } \\
\text { cytokine } \\
\text { concentrations in } \\
\text { pigs }\end{array}$ & Suínos & Bokashi & Suínos & $\begin{array}{l}\text { Kits } r \text { ELISA } \\
\text { foram utilizados } \\
\text { para determinar } \\
\text { os níveis de } \\
\text { citocinas no soro } \\
\text { porcino e nos } \\
\text { sobrenadantes } \\
\text { das culturas de } \\
\text { PBMC. }\end{array}$ \\
\hline $\begin{array}{l}\text { Baldotto \& } \\
\text { Baldotto, } \\
2016\end{array}$ & $\begin{array}{l}\text { Initial performance } \\
\text { of corn in response } \\
\text { to treatment of seeds } \\
\text { with humic acids } \\
\text { isolated from } \\
\text { bokashi }\end{array}$ & Milho & $\begin{array}{c}\text { Ácidos } \\
\text { húmicos } \\
\text { isoladas } \\
\text { de } \\
\text { bokashi. }\end{array}$ & $\begin{array}{l}\text { Desenvolvimento } \\
\text { da espécie }\end{array}$ & $\begin{array}{l}\text { Características de } \\
\text { crescimento dos } \\
\text { sistemas de } \\
\text { brotação e raízes } \\
\text { foram avaliadas }\end{array}$ \\
\hline
\end{tabular}

Fonte: Autores (2019).

Dos dois artigos apresentados na área de veterinária temos Laskowska, Jarosz \& Gradzki, (2017) que buscou avaliar o efeito da suplementação alimentar com EM na concentração de citocinas pró e anti-inflamatórias no soro e em cultura de PBMCs com e sem a estimulação com ConA em suínos, concluindo que a suplementação de ração para suínos com EM Bokashi ativa a resposta imune mediada por células e humoral, garantindo que o equilíbrio Th1 / Th2 seja mantido e melhorando os processos imunológicos que protegem o organismo contra infecções.

E também podemos observar Baldotto \& Baldotto, 2016 que buscando estudar o desempenho inicial de plantas indicadoras de milho em resposta à aplicação de diferentes concentrações de ácidos húmicos isoladas de bokashi, os resultados mostraram que os ácidos húmicos extraídos do bokashi tiveram efeitos positivos no desempenho inicial do milho. 


\section{Considerações Finais}

Por meio desta pesquisa de revisão pode-se concluir que mais de 50\% dos artigos publicados sobre bokashi nos últimos 20 anos de pesquisas são voltados para a área de agricultura e ciências biológicas e ciências ambientais, demonstrando que outras áreas como veterinária, ciências sociais, química, multidisciplinar, energia, engenharia química, imunologia e microbiologia, bioquímica, genética e biologia molecular, são escassas em pesquisas relacionadas ao adubo. Portanto, através desta revisão foi possível verificar que existem lacunas sobre este tema que possibilitarão a abertura de novas pesquisas, para o mercado agrícola e de produção em orgânicos, por se tratar de um fertilizante concentrado, rico em nitrogênio, fósforo e potássio, podendo ser utilizando em substituição dos fertilizantes químicos tradicionais.

Sugere-se então para trabalhos futuros maior foco de estudos relacionados ao bokashi nas áreas de veterinária, ciências sociais, química, multidisciplinar, energia, engenharia química, imunologia e microbiologia, bioquímica, genética e biologia molecular, que talvez possa trazer visões diferentes de atuação e mecanismos de nutrição do adubo.

\section{Referências}

Abdul Aziz, N. I. H., Hanafiah, M. M., Mohamed Ali, M. Y. (2019). Sustainable biogas production from agrowaste and effluents - A promising step for small-scale industry income. Renewable Energy, 132, 363-369.

Alattar, M. A., Green, T. R., Henry, J., Gulca, V., Tizazu, M., Bergstrom, R. Popa, R. (2012). Effect of microaerobic fermentation in preprocessing fibrous lignocellulosic materials. Applied Biochemistry and Biotechnology, 167(4), 909-917.

Álvarez-Solís, J. D., Mendoza-Núñez, J. A., León-Martínez, N. S., Castellanos-Albores, J., Gutiérrez-Miceli, F. A. (2016). Effect of Bokashi and vermicompost leachate on yield and quality of pepper (Capsicum annuum) and onion (Allium cepa) under monoculture and intercropping cultures. Ciencia e Investigacion Agraria, 43(2), 243-252. 
Álvarez-Solís, J. D., Gómez-Velasco, D. A., León-Martínez, N. S., Gutiérrez-Miceli, F. A. (2010). Integrated management of inorganic and organic fertilizers in maize cropping. Agrociencia, 44(5), 575-586.

Aulinas Masó, M., Bonmatí Blasi, A. (2008). Evaluation of composting as a strategy for managing organic wastes from a municipal market in Nicaragua. Bioresource Technology, 99(11), 5120-5124.

Baldotto, M. A., Baldotto, L. E. B. (2016). Initial performance of corn in response to treatment of seeds with humic acids isolated from bokashi. Revista Ceres, 63(1-62), 62-67.

Barajas-Aceves, M., Camarillo-Ravelo, D., Juárez-Sánchez, F., Rodríguez-Vázquez, R. (2012). Lead and zinc distribution in Brassica juncea and arid soil amended with mine tailings and bokashi. Fresenius Environmental Bulletin, 21(9), 2626-2637.

Barajas-Aceves, M., Rodríguez-Vázquez, R. (2013). Effects of organic amendments on the mobility of $\mathrm{Pb}$ and $\mathrm{Zn}$ from mine tailings added to semi-arid soils. Journal of Environmental Science and Health - Part B Pesticides, Food Contaminants, and Agricultural Wastes, 48(3), 226-236.

Bautista-Cruz, A., Cruz Domínguez, G., Rodríguez Mendoza, M. N., Pérez Pacheco, R., Robles, C. (2014). Effect of compost and slow-release fertilizers addition on soil biochemistry and yield of maize (Zea mays L.) in Oaxaca, Mexico. Revista de la Facultad de Ciencias Agrarias, 46(1), 181-193.

Boechat, C. L., Santos, J. A. G., Accioly, A. M. A. (2013). Net mineralization nitrogen and soil chemical changes with application of organic wastes with 'Fermented Bokashi Compost'. Acta Scientiarum - Agronomy, 35(2), 257-264.

Borda-Molina, D., Pardo-García, J. M., Montaña-Lara, J. S., Martínez-Salgado, M. M. (2011). Influence of organic matter and Azotobacter nigricans on a Stevia rebaudiana B. Plantation. Universitas Scientiarum, 16(3), 282-293. 
Castro, A., Batista, N. S., Latawiec, A. E., Rodrigues, A., Strassburg, B., Silva, D., Araujo, E. de Moraes, L. F. D., Guerra, J. G., Galvão, G., Alves-Pinto, H., Mendes, M., Santos, J. S., Rangel, M. C., Figueredo, M., Cornelissen, G., Hale, S. (2018). The effects of Gliricidiaderived biochar on sequential maize and bean farming. Sustainability (Switzerland), 10(3).

Curi, N.; Ker, J.C., Novais, R.F., Vidal-Torrado, P., Schaefer, C.E.G.R. (2017). Pedologia: solos dos biomas brasileiros. Viçosa: Sociedade Brasileira de Ciência do Solo.

Daiss, N., Lobo, M. G., Socorro, A. R., Brückner, U., Heller, J., Gonzalez, M. (2008). The effect of three organic pre-harvest treatments on Swiss chard (Beta vulgaris L. var. cycla L.) quality. European Food Research and Technology, 226 (3), 345-353.

Daiss, N., Lobo, M. G., Gonzalez, M. (2008). Changes in postharvest quality of swiss chard grown using 3 organic preharvest treatments. Journal of Food Science, 73(6), 314-320.

Dias-Arieira, C. R., Mattei, D., Puerari, H. H., Ribeiro, R. C. F. (2015). Use of organic amendments in the management of root-knot nematode in lettuce. Horticultura Brasileira, 33(4), 488-492.

Ekebafe, M. O., Ekebafe, L. O., Ugbesia, S. O. (2015). Biochar composts and composites. Science Progress, 98(2), 169-176.

Esatu, W., Melesse, A., Dessie, T. (2011). Effect of effective microorganisms on growth parameters and serum cholesterol levels in broilers. African Journal of Agricultural Research, 6(16), 3841-3846.

Fernandes, S. J. O., Titon, M., Santana, R. C., Antonini, L. G., Nogueira, G. S., Filho, N. F. B. (2011). Survival and growth of eucalypts clones seedlings in response to organic fertilizer application. Cerne, 17(4), 601-606.

Ferreira, J. C. A., Hernandes, I., Brito, O. D. C., Cardoso, M. R., Dias-Arieira, C. R. (2017). Dosages of bokashi in the control of Meloidogyne javanica in lettuce, in greenhouse. Horticultura Brasileira, 35(2), 224-229. 
Formowitz, B., Elango, F., Okumoto, S., Müller, T., Buerkert, A. (2007). The role of "effective microorganisms" in the composting of banana (Musa ssp.) residues. Journal of Plant Nutrition and Soil Science, 170(5), 649-656.

França, F. C. T., da Silva, E. C., Pedrosa, M. W., Carlos, L. A., Maciel, G. M. (2016). Tomato yield and quality under various combinations of organic compost. Bioscience Journal, 32(5), $1147-1154$.

Gómez-Velasco, D. A., Álvarez-Solís, J. D., Ruiz-Valdiviezo, V. M., Abud-Archila, M., Montes-Molina, J. A., Dendooven, L., Gutiérrez-Miceli, F. A. (2014). Enzymatic Activities in Soil Cultivated with Coffee (Coffea arabica L. cv. 'Bourbon') and Amended with Organic Material. Communications in Soil Science and Plant Analysis, 45(19), 2529-2538.

Goyal, S., Inubushi, K., Kato, S., Xu, H. L., Umemura, H. (1999). Effect of anaerobically fermented manure on the soil organic matter, microbial properties and growth of Spinach under greenhouse conditions. Indian Journal of Microbiology, 39(4), 211-216.

Hafle, O. M., dos Santos, V. A., Ramos, J. D., da Cruz, M. C., de Melo, P. C. (2009). Production of seedlings of papaya tree using bokashi and lithothamnium. Revista Brasileira de Fruticultura, 31(1), 245-251.

Hanafiah, M. M., Mohamed Ali, M. Y., Abdul Aziz, N. I. H., Ashraf, M. A., Halim, A. A., Lee, K. E., Idris, M. (2017). Biogas production from goat and chicken manure in Malaysia. Applied Ecology and Environmental Research, 15(3), 529-535.

Hikamah, S. R., Sudiarti, D., Hasbiyati, H. (2019). The effectiveness of bokashi against growth of mustard Brassica juncea L., Brassica rapa L. Pokcay And Maize Zea mays L. IOP Conference Series: Earth and Environmental Science,243, 012072.

Hoshino, R. T., Alves, G. A. C., Melo, T. R., Barzan, R. R., Fregonezi, G. A. F., Faria, R. T. (2016). Mineral and organic fertilization influence on the development of cattlianthe 'chocolate drop'. Horticultura Brasileira, 34(4), 475-482. 
Jaramillo-López, P. F., Ramírez, M. I., Pérez-Salicrup, D. R. (2015). Impacts of Bokashi on survival and growth rates of Pinus pseudostrobus in community reforestation projects. Journal of Environmental Management, 150, 48-56.

Kale, D. K., Anthappan, P. D. (2012). Sustainable treatment of wastewater using effective microorganisms. Journal of Pure and Applied Microbiology, 6(1), 333-338.

Karimuna, L., Leomo, S., Indriyani, L. (2012). Improvement of Maize and Peanut production in intercropping system through the application of organic fertilizer and mulch in ultisol soil. Chiang Mai University Journal of Natural Sciences, 11(1), 387-394.

Laskowska, E., Jarosz, Ł., Grądzki, Z. (2019). Effect of Multi-Microbial Probiotic Formulation Bokashi on Pro- and Anti-Inflammatory Cytokines Profile in the Serum, Colostrum and Milk of Sows, and in a Culture of Polymorphonuclear Cells Isolated from Colostrum. Probiotics and Antimicrobial Proteins, 11(1), 220-232.

Laskowska, E., Jarosz, Ł., Grądzki, Z. (2017). The effect of feed supplementation with effective microorganisms (EM) on pro- and anti-inflammatory cytokine concentrations in pigs. Research in Veterinary Science, 115, 244-249.

Lasmini, S. A., Nasir, B., Hayati, N., Edy, N. (2018). Improvement of soil quality using bokashi composting and NPK fertilizer to increase shallot yield on dry land. Australian Journal of Crop Science, 12(11), 1743-1749.

Lima, C. E. P., Fontenelle, M. R., Silva, L. R. B., Soares, D. C., Moita, A. W., Zandonadi, D. B., Souza, R. B. Lopes, C. A. (2015). Short-term changes in fertility attributes and soil organic matter caused by the addition of em Bokashis in two tropical soils. International Journal of Agronomy, 17(2), 56-70.

Lurling, M., Tolman, Y., Euwe, M. (2009). Mitigating cyanobacterial blooms: How effective are 'effective microorganisms'? Lakes and Reservoirs: Research and Management, 14(4), 353-363. 
Lurling, M., Tolman, Y., Van Oosterhout, F. (2010). Cyanobacteria blooms cannot be controlled by Effective Microorganisms (EM®) from mud- or Bokashi-balls. Hydrobiologia, 646(1), 133-143.

Mayer, J., Scheid, S., Widmer, F., Fließbach, A., Oberholzer, H. R. (2010). How effective are 'Effective microorganisms ${ }^{\circledR}(\mathrm{EM})$ '? Results from a field study in temperate climate. Applied Soil Ecology, 46(2), 230-239.

Morales, E. B., Peñafiel, M., Barahona, M., Mohiddin, G. J., Cuaycal, A. E., Aguas, S. B. (2016). Effect of silicon in Taro crop (Colocasia esculenta) in combination with two levels of organic matter. Asian Journal of Microbiology, Biotechnology and Environmental Sciences, 18(4), 809-816.

Mponya, C. S., Sharma, S. K., Meena, R. H., Koshik, M. K. (2014). Effect of different organic manures on yield and nutrient uptake by maize (Zea mays L.). Ecology Environment and Conservation, 20(2), 519-522.

Ndona, R. K., Friedel, J. K., Spornberger, A., Rinnofner, T., Jezik, K. (2011). 'Effective Micro-organisms' (EM): An Effective Plant Strengthening Agent for Tomatoes in Protected Cultivation. Biological Agriculture \& Horticulture, 27(2), 189-203.

Nikitin, A. N., Cheshyk, I. A., Gutseva, G. Z., Tankevich, E. A., Shintani, M., Okumoto, S. (2018). Impact of effective microorganisms on the transfer of radioactive cesium into lettuce and barley biomass. Journal of Environmental Radioactivity, 192, 491-497.

Nurhidayati, A., Nurhidayati, Q., Kusuma, Z. Sudarto, (2014). Effectiveness of various mulch towards chemical fertility, soil erosion and crops production of potato (Solanum tuberosum, Linn) in Andisol of Ranupani, East Java. International Journal of ChemTech Research, 6(11), 4796-4802.

Ourives, O. E. A., Souza, G. M., Tiritan, C. S., Santos, D. H. (2010). Organic fertilizer as phosphorus supplier for Brachiaria brizantha cv. Marandú. Pesquisa Agropecuaria Tropical, 40(2), 126-132. 
Pandit, N. R., Schmidt, H. P., Mulder, J., Hale, S. E., Husson, O., Cornelissen, G. (2019). Nutrient effect of various composting methods with and without biochar on soil fertility and maize growth. Archives of Agronomy and Soil Science.

Park \& Kremer (2002). Establishment of an inoculated bacterial strain on plant root surfaces in soils with different microbial community. Journal of Applied Biological Chemistry, 53(3), 379-383.

Pei-Sheng, Y., Hui-Lian, X. (2002). Influence of EM bokashi on nodulation, physiological characters and yield of peanut in nature farming fields. Journal of Sustainable Agriculture, 19(4), 105-112.

Peralta-Antonio, N., Becerril-Román, A. E., Rebolledo-Martínez, A., Jaén-Contreras, D. (2015). Nutritional foliar status of three mango cultivars fertilized with organic amendments. Idesia, 33(3), 65-72.

Peralta-Antonio, N., Rebolledo-Martínez, A., Becerril-Román, A. E., Jaén-Contreras, D., Del Angel-Pérez, A. L. (2014). Response to organic fertilization in mango cultivars: Manila, Tommy Atkins and Ataulfo. Journal of Soil Science and Plant Nutrition, 14(3), 688-700.

Pereira, A. S., Shitsuka, D. M, Parreira, F. J., Shitsuka, R. (2018). Metodologia da pesquisa científica. [eBook]. Santa Maria. Ed. UAB / NTE / UFSM. Available at: https://repositorio.ufsm.br/bitstream/handle/1/15824/Lic_Computacao_MetodologiaPesquisa-Cientifica.pdf? sequence $=1$

Pérez, A., Céspedes, C., Núñez, P. (2008). Physical, chemical and biological characterization of applied organic amendments in crop production in Dominican Republic. Revista de la Ciencia del Suelo y Nutricion Vegetal, 8(3), 10-29.

Pérez-Godínez, E. A., Lagunes-Zarate, J., Corona-Hernández, J., Barajas-Aceves, M. (2017). Growth and reproductive potential of Eisenia foetida (Sav) on various zoo animal dungs after two methods of pre-composting followed by vermicomposting. Waste Management, 64, 6778. 
Quiroz, M. \& Flores, F. (2019). Nitrogen availability, maturity and stability of bokashi-type fertilizers elaborated with different feedstocks of animal origin. Archives of Agronomy and Soil Science, 65(6), 867-875.

Resman, T., Tufaila, M., Ansi, A., Halim, A., Arma, M. J., Harlis, W. O. (2018). Effect of bokashi fertilizer on growth and yield of local maize from Muna Island under net house treatment in West Muna Southeast Sulawesi, Indonesia. Bioscience Research, 15(3), 15201527.

Reyna-Ramírez, C. A., Rodríguez-Sánchez, L. M., Vela-Correa, G., Etchevers-Barra, J., Fuentes-Ponce, M. (2018). Redesign of the traditional Mesoamerican agroecosystem based on participative ecological intensification: Evaluation of the soil and efficiency of the system. Agricultural Systems, 165, 177-186.

Rezende, A. M. F. A., Tomita, C. K., Uesugi, C. H. (2008). Cupric fungicides, benzalconium chlorides and liquid bioactive compost (Bokashi): Phytotoxicity and control of guava bacterial blight caused by Erwinia psidii. Tropical Plant Pathology, 33(4), 288-294.

Ribeiro, M. N. O., Almeida, E. F. A., Reis, S. N., Carvalho, L. M., Figueiredo, J. R. M., Ribeiro Júnior, P. M. (2016). Manure effect on the incidence of rose diseases in the Integrated Production System. Horticultura Brasileira, 34(3), 412-415.

Roldi, M., Dias-Arieira, C. R., Severino, J. J., De Melo Santana, S., Dadazio, T. S., Marini, P. M., Mattei, D. (2013). Use of organic amendments to control meloidogyne incognita on tomatoes. Nematropica, v. 43(1), 49-55.

Saldaña Y Hernández, M. I., Álvarez, R. G., Rivera Cruz, M. D. C., Solís, J. D. A., García, C. F. O., Fernández, J. M. P. (2014). Effect of organic fertilizers on soil microbial dynamics and production of Alpinia purpurata (Vieill) K. Schum. Interciencia, 39(11), 809-815.

Saldaña y Hernández, M. I., Gómez-Álvarez, R., Rivera-Cruz, M. C., Álvarez-Solís, J. D., Pat-Fernández, J. M., Ortiz-García, C. F. (2014). The influence of organic fertilizers on the chemical properties of soil and the production of Alpinia purpurata. Ciencia e Investigacion Agraria, 41(2), 215-224. 
Shin, K., van Diepen, G., Blok, W., van Bruggen, A. H. C. (2017). Variability of Effective Micro-organisms (EM) in bokashi and soil and effects on soil-borne plant pathogens. Crop Protection, 99, 168-176.

Shingo, G. Y., Ventura, M. U. (2009). Collard greens yield with mineral and organic fertilization. Semina: Ciencias Agrarias, 30(3), 589-594.

Siregar, M. J. (2018). Characteristic of husk charcoal, bokashi compost, and wood charcoal as biofilter filler on application of Ammonia 5 Percent. International Journal of Engineering and Technology (UAE), 7(4), 53-56.

Souza, P. P. (2018). Influência da adubação orgânica e mineral no desenvolvimento inicial na cultura da abobrinha-italiana (Cucurbita pepo). Revista Científica Multidisciplinar Núcleo do Conhecimento, 2(3), 133-145.

Sumarni, T., Aini, N., Fajriani, S. (2017). The application of compost and arbuscularmy corrhizal fungi to increase efficiency of inorganic fertilization on maize (Zea mays L.). Bioscience Research, 14(4), 1057-1063.

Urra, J., Alkorta, I., Lanzén, A., Mijangos, I., Garbisu, C. (2019). The application of fresh and composted horse and chicken manure affects soil quality, microbial composition and antibiotic resistance. Applied Soil Ecology, 135, 73-84.

Vetayasuporn, S. (2006). Effects of biological and chemical fertiliser on growth and yield of glutinous corn production. Journal of Agronomy, 5(1), 1-4.

Xavier, M. C. G.; Santos, C. A.; Costa, E. S. P.; Carmo, M. G. F. (2019). Cabbage yield as a function of bokashi doses. Revista De Agricultura Neotropical, 6(1), 17-22.

Xu, H. L., Wang, R., Mridha, M. A. U. (2000). Effects of organic fertilizers and a microbial inoculant on leaf photosynthesis and fruit yield and quality of tomato plants. Journal of Crop Production, 3(1), 173-182. 
Xu, H. L., Wang, X., Wang, J. (2000). Modeling photosynthesis decline of excised leaves of sweet corn plants grown with organic and chemical fertilization. Journal of Crop Production, $3(1), 245-253$.

Yamada, K., Xu, H. L. (2000). Properties and applications of an organic fertilizer inoculated with effective microorganisms. Journal of Crop Production, 3(1), 255-268.

Zaman, M., Ahmed, M., Gogoi, P. (2010). Effect of Bokashi on plant growth, yield and essential oil quantity and quality in Patchouli (Pogostemon cablin Benth.). Biosciences Biotechnology Research Asia, 7(1), 383-387.

\title{
Porcentagem de contribuição de cada autor no manuscrito
}

\author{
Nelma Ferreira de Paulo Vicente - 17,5\% \\ Érica Alves Marques Marafeli - 30\% \\ Júlia Assunção de Castro Oliveira - 17,5\% \\ José Luiz Choiti Tomita - 17,5\% \\ Roberta Hilsdorf Piccoli - 17,5\%
}

